\title{
Tropical Cyclone-Induced Ocean Response: A Comparative Study of the South China Sea and Tropical Northwest Pacific*, ${ }^{*}$
}

\author{
WEI MEI \\ Scripps Institution of Oceanography, University of California, San Diego, La Jolla, California \\ CHUN-CHI LIEN AND I.-I. LIN \\ Department of Atmospheric Sciences, National Taiwan University, Taipei, Taiwan \\ SHANG-PING XIE \\ Scripps Institution of Oceanography, University of California, San Diego, La Jolla, California, and \\ International Pacific Research Center, University of Hawai' $i$ at Mānoa, Honolulu, Hawaii
}

(Manuscript received 21 September 2014, in final form 23 February 2015)

\begin{abstract}
The thermocline shoals in the South China Sea (SCS) relative to the tropical northwest Pacific Ocean (NWP), as required by geostrophic balance with the Kuroshio. The present study examines the effect of this difference in ocean state on the response of sea surface temperature (SST) and chlorophyll concentration to tropical cyclones (TCs), using both satellite-derived measurements and three-dimensional numerical simulations. In both regions, TC-produced SST cooling strongly depends on TC characteristics (including intensity as measured by the maximum surface wind speed, translation speed, and size). When subject to identical TC forcing, the SST cooling in the SCS is more than 1.5 times that in the NWP, which may partially explain weaker TC intensity on average observed in the SCS. Both a shallower mixed layer and stronger subsurface thermal stratification in the SCS contribute to this regional difference in SST cooling. The mixed layer effect dominates when TCs are weak, fast-moving, and/or small; and for strong and slow-moving TCs or strong and large TCs, both factors are equally important.

In both regions, TCs tend to elevate surface chlorophyll concentration. For identical TC forcing, the surface chlorophyll increase in the SCS is around 10 times that in the NWP, a difference much stronger than that in SST cooling. This large regional difference in the surface chlorophyll response is at least partially due to a shallower nutricline and stronger vertical nutrient gradient in the SCS. The effect of regional difference in upper-ocean density stratification on the surface nutrient response is negligible. The total annual primary production increase associated with the TC passage estimated using the vertically generalized production model in the SCS is nearly 3 times that in the NWP (i.e., $6.4 \pm 0.4 \times 10^{12}$ versus $2.2 \pm 0.2 \times 10^{12} \mathrm{~g} \mathrm{C}$ ), despite the weaker TC activity in the SCS.
\end{abstract}

\footnotetext{
* International Pacific Research Center Publication Number 1115 and School of Ocean and Earth Science and Technology Publication Number 9328.

${ }^{+}$Supplemental information related to this paper is available at the Journals Online website: http://dx.doi.org/10.1175/JCLI-D-1400651.s1.
}

Corresponding author address: Wei Mei, Scripps Institution of Oceanography, University of California, San Diego, 9500 Gilman Drive, \#0206, La Jolla, CA 92093-0206.

E-mail:wmei@ucsd.edu

\section{Introduction}

Each year tropical cyclones (TCs) visit both the South China Sea (SCS) - a semienclosed sea in the southwest corner of the North Pacific - and the tropical northwest Pacific Ocean (NWP; defined here as a region covering $5^{\circ}$ $22^{\circ} \mathrm{N}$ and $122^{\circ}-140^{\circ} \mathrm{E}$ ) [see, e.g., Lin (2012) and Mei et al. (2015a) for the track distribution]. TCs over these two regions exhibit significant differences in various aspects, particularly the intensity as measured by the maximum surface wind speed. Figure 1 compares the distribution of 


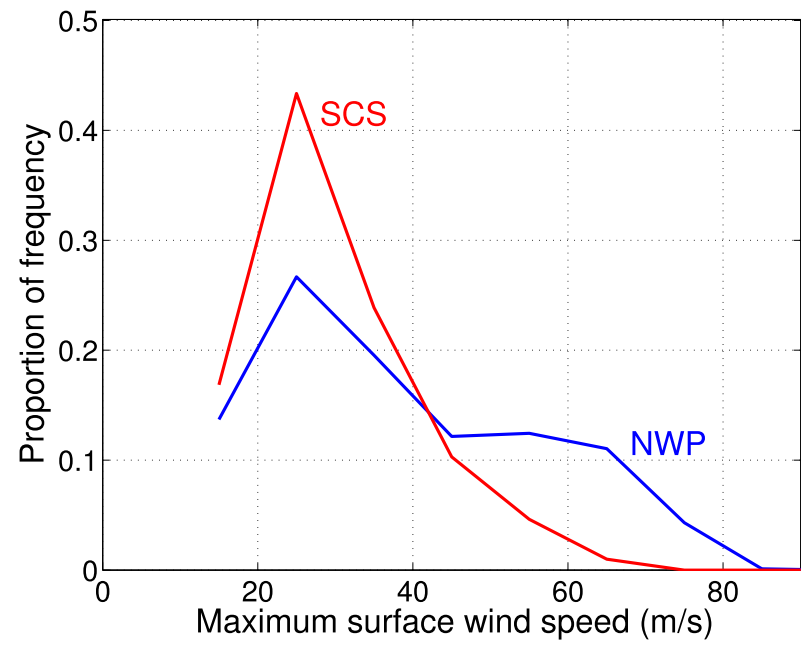

FIG. 1. Proportion of the frequency of TC intensity observations at 6-h intervals over the NWP (blue) and SCS (red).

percentage frequency of instantaneous TC intensity at 6-h intervals in the SCS and NWP. TCs in the NWP on average are more intense than those in the SCS, with the former region experiencing more TCs of intensity above $40 \mathrm{~m} \mathrm{~s}^{-1}$ in percentage. Given that TCs in these two regions pose severe threats to a huge population in East and Southeast Asia, understanding controlling factors for TC intensity in these regions is of great importance.

While differences in geographic features (particularly the land surrounding the SCS) may account for some of the differences in TC intensity, the oceanic state can also play a role, in addition to atmospheric conditions (such as low-level vorticity). Figure $2 \mathrm{a}$ shows the zonalvertical cross section of ocean temperatures across the northward-flowing Kuroshio, which anchors a steep slope of the thermocline across the Luzon Strait with a much shallower thermocline in the SCS than the NWP. Local winds also contribute to the interbasin difference in the thermocline depth [ $O(10) \mathrm{m}$; e.g., Jian et al. 2001]. The East Asian monsoon drives strong upwelling and thereby lifts the thermocline in the SCS (e.g., Xie et al. 2003), while the large-scale wind forcing favors an oceanic downwelling in the NWP.

The differences in the upper-ocean condition can translate into distinct effects on TC intensity by affecting the magnitude of TC-generated sea surface temperature (SST) cooling (e.g., Shay et al. 2000; Wu et al. 2007; Lin et al. 2008, 2009a; Vincent et al. 2014; Mei et al. 2015b). By mixing the surface warm water with colder water underneath, TCs cool the surface water and warm the subsurface water (e.g., Price 1981). The amplitude of the surface cooling strongly depends on prestorm mixed layer depth and stratification in the thermocline, in addition to TC characteristics such as intensity and translation speed (e.g., Price 1981; Lin et al. 2009b; Knaff et al. 2013; Mei and Pasquero 2013). Since the mixed layer is in general shallower in the SCS than in the NWP, the TC-generated SST cooling is expected to be stronger in the former region for the same atmospheric conditions. Figure $2 b$ shows the SST cooling generated by Typhoon Nesat in 2011 as an example. Nesat moved at a relatively steady speed but produced significantly different amplitudes of SST cooling in the SCS and NWP. Although the TC intensity was slightly stronger
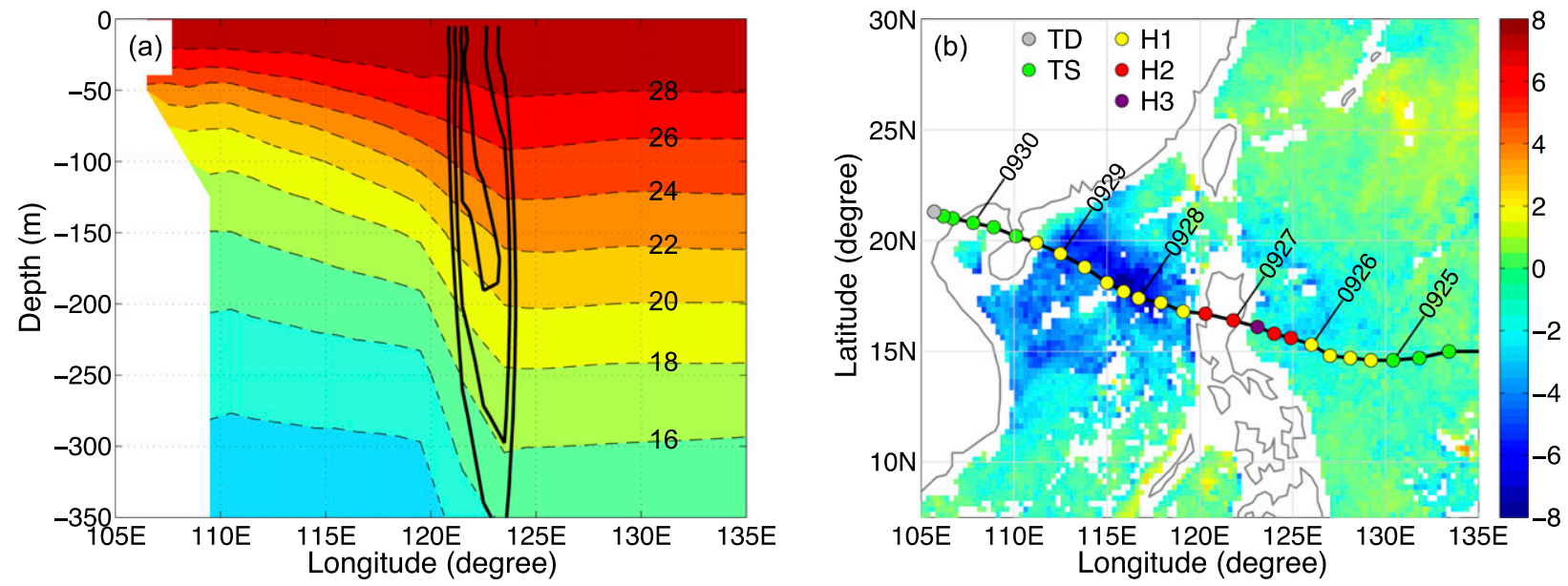

FIG. 2. (a) Cross section of climatological summer temperature (shading and dashed black contours; ${ }^{\circ} \mathrm{C}$ ) and meridional velocity (solid black contours; starting at $0.1 \mathrm{~m} \mathrm{~s}^{-1}$ with an interval of $0.025 \mathrm{~m} \mathrm{~s}^{-1}$ ) averaged between $15^{\circ}$ and $22^{\circ} \mathrm{N}$. Note that this plot is only for schematic purposes and it may not satisfy the geostrophic relation in a strict way as the temperature and velocity data are respectively from the World Ocean Atlas 2009 and ECCO. (b) SST changes (color shading; ${ }^{\circ} \mathrm{C}$ ) induced by Typhoon Nesat during 23-30 Sep 2011. Thick black line shows typhoon track and colored circles denote typhoon intensity. Times of typhoon passage are selectively labeled at 0000 UTC of each day in the form of a two-digit month and day (i.e., mmdd). Note that the colorbar applies only to (b). 
over the NWP than over the SCS, the SST cooling was generally weaker than $3^{\circ} \mathrm{C}$ in the former region, whereas the cooling exceeded $7^{\circ} \mathrm{C}$ over a large area in the latter. The TC-induced instantaneous cooling is a negative feedback onto TC intensity by reducing air-sea heat fluxes (e.g., Brand 1971; Emanuel 1999; Schade and Emanuel 1999; Bender and Ginis 2000; Cione and Uhlhorn 2003; Bell and Montgomery 2008; Mei et al. 2012; Vincent et al. 2014). As shown in Mei et al. (2012), a strong SST cooling generally tends to reduce the rate of TC intensification and may even cause the TC to decay. An SST cooling of $3^{\circ} \mathrm{C}$ barely allows a TC to intensify. Therefore, a good characterization of the TC-induced SST cooling may largely help improve understanding and prediction of TC intensity.

In the past decades, numerous studies have been devoted to quantifying and understanding the SST cooling generated by individual TCs in the SCS and NWP [see Chu et al. (2000), Lin et al. (2003a,b), Zheng and Tang (2007), Shang et al. (2008), Tseng et al. (2010), Chiang et al. (2011), Tsai et al. (2012), and Ko et al. (2014) for cases in the SCS and Kuo et al. (2011), Lin (2012), and Yang et al. (2012) for cases in the NWP]. Chu et al. (2000) were among the first to study the response of the SCS to TCs by examining the case of Typhoon Ernie (1996) using both observed SSTs and a $20-\mathrm{km}$ horizontal resolution ocean model. They found the responses in marginal seas (e.g., the SCS in their study) share many similarities with those in the open ocean, such as the rightward-biased SST cooling with respect to the TC track caused by the stronger near-inertial currents on that side due to the resonance effect. Using more accurate satellite-derived observations, Lin et al. (2003b) and Chiang et al. (2011) identified that the local SST cooling induced by Typhoon Kai-Tak (2000) in the SCS was up to $10^{\circ} \mathrm{C}$ and showed that such a dramatic cooling is due to the slow-moving speed of Kai-Tak and the shallow prestorm mixed layer in the SCS. The TC-generated SST cooling in the NWP is relatively weak by comparison (e.g., Kuo et al. 2011; Lin 2012; Yang et al. 2012).

These previous case studies have greatly enhanced our appreciation of TCs' effect on the SST and advanced our understanding of the underlying mechanisms (such as the role of a shallow prestorm mixed layer in producing a strong cooling). The amplitude of the cooling reported, however, varies strongly from case to case [see, e.g., Lin (2012) for a comparison of 11 cases], and a climatological assessment is still lacking. This also holds true for another aspect of TC-induced oceanic responseelevated chlorophyll concentration, which may serve as a proxy of ocean upwelling and mixing. Although many studies have examined the chlorophyll response to individual TCs (e.g., Lin et al. 2003b; Zheng and Tang 2007; Shang et al. 2008; Zhao et al. 2008; Sun et al. 2010; Lin 2012; Yang et al. 2012), no studies have addressed this issue from a climatological perspective in the SCS and NWP as has been performed in the North Atlantic by Hanshaw et al. (2008).

To fill these gaps, this study systematically characterizes and compares both the SST and chlorophyll responses to TCs between the SCS and NWP by performing a composite analysis and using available satellite-derived SST and chlorophyll data. After introducing the data and methods in use in section 2, we explore the TC-generated SST response in both the SCS and NWP and understand the physical mechanisms responsible for the differences between these two regions in section 3 . We then proceed to study and compare the response of chlorophyll in section 4 . Section 5 is a summary.

\section{Data and methods}

\section{a. SST data, chlorophyll concentration data, and TC track data}

The SST data during December 1997-October 2013 derived from the Tropical Rainfall Measuring Mission (TRMM) Microwave Imager (TMI; Wentz et al. 2000) are used to calculate the SST anomaly generated by TCs. The description of this dataset parallels that of Mei and Pasquero (2013), as follows: This dataset has a spatial resolution of $0.25^{\circ} \times 0.25^{\circ} .{ }^{1}$ It has a daily temporal resolution including ascending and descending orbit segments. The daily average value is obtained by averaging the ascending and descending passes or assigning the available one if only one pass is available; missing values are left unfilled. On each grid, the obtained daily data are preprocessed to remove the climatological seasonal cycle and long-term linear trend before any further calculations.

The chlorophyll concentration during July 2002October 2013 estimated from the Moderate Resolution Imaging Spectroradiometer (MODIS) satellite measurements (Savtchenko et al. 2004) is used to study the TC-induced chlorophyll response. This dataset has a spatial resolution of $9 \mathrm{~km}$ and a daily temporal resolution. The invalid measurements due to the presence of cloud cover are not included in our calculations. [Using data from the Sea-Viewing Wide Field-of-View Sensor (SeaWiFS) produces very similar results.]

The TC track data in use are from the Joint Typhoon Warning Center (JTWC) best-track dataset (Chu et al. 2002). This product provides the location and intensity of TCs at a 6-h interval, and here, to be consistent with

\footnotetext{
${ }^{1}$ Note that the local maximum cooling may not be captured owing to the not so fine resolution of the TMI data in use. This effect, however, does not significantly affect our conclusions in this study, which focuses on relatively large spatial scales.
} 
TABLE 1. TC groups categorized based on TC intensity and translation speed. The numbers in the NWP and SCS columns under case number show the number of 6-h observations, while those in parentheses show the effective number of observations. The effective number of observations is approximated as the number of observations that are separated by at least $150 \times \sqrt{2} \approx 212 \mathrm{~km}$ in distance or at least 10 days in time.

\begin{tabular}{lcccc}
\hline \hline & & & \multicolumn{2}{c}{ Case No. } \\
\cline { 4 - 5 } \multicolumn{1}{c}{ TC group } & Intensity & speed & NWP & SCS \\
\hline Weak and slow & $\leq 33 \mathrm{~m} \mathrm{~s}^{-1}$ & $\leq 3 \mathrm{~m} \mathrm{~s}^{-1}$ & $477(135)$ & $664(164)$ \\
Strong and slow & $>33 \mathrm{~m} \mathrm{~s}^{-1}$ & $\leq 3 \mathrm{~m} \mathrm{~s}^{-1}$ & $216(62)$ & $94(29)$ \\
Weak and fast & $\leq 33 \mathrm{~m} \mathrm{~s}^{-1}$ & $>3 \mathrm{~m} \mathrm{~s}^{-1}$ & $1746(785)$ & $1094(479)$ \\
Strong and fast & $>33 \mathrm{~m} \mathrm{~s}^{-1}$ & $>3 \mathrm{~m} \mathrm{~s}^{-1}$ & $796(368)$ & $299(138)$ \\
\hline
\end{tabular}

the availability of the SST data, we only use the track data since December 1997.

\section{b. Methods}

We perform composite analysis to obtain the average features of the SST and chlorophyll response, following the method described in Mei et al. (2012) and Mei and Pasquero (2013). For each TC location, we obtain the temporal evolution of SST and chlorophyll concentration averaged over a TC-centered $3^{\circ} \times 3^{\circ}$ box before, during, and after the TC passage, using the preprocessed SST data and the original chlorophyll data. The obtained boxaveraged SST and chlorophyll for each storm location and time are then used to get the composites of the SST and chlorophyll evolution in terms of TC intensity, translation speed, and/or size, and the anomalies in SST and chlorophyll in the poststorm stage are defined with respect to a 1-month average prestorm condition at the same location. $^{2}$ Then the TC-generated SST cooling is defined as the maximum negative SST anomaly, which usually appears on the day right after the TC passage. The results presented in this study are not significantly sensitive to the size of the box in use for the calculation.

To examine the dependence of TC-produced anomalies in SST and chlorophyll on TC intensity and translation speed, we divide the storms into four groups shown in Table 1 . The limited number of TC cases does not allow us to use small bins, such as $5 \mathrm{~m} \mathrm{~s}^{-1}$ for TC intensity, as in Mei and Pasquero (2013). We also explore the dependence of SST response on TC size. The JTWC TC data provide information on TC size (defined

\footnotetext{
${ }^{2}$ Although we have removed the seasonality and long-term linear trend before performing composite analysis for the SST data, there is anomalous warming before the TC passage (see, e.g., Mei and Pasquero 2013, their Fig. 12). This is the reason why we define the SST anomaly with respect to a 1-month average prestorm condition.
}

as the radius of the last closed isobar) since 2001 for around $75 \%$ of the $6-\mathrm{h}$ observations. Because of the limited sample size and considering the positive relationship between averaged TC size and intensity (e.g., Mei and Pasquero 2013, their Fig. 6), we restrict this analysis to TCs with an intensity between 17.5 and $43.0 \mathrm{~m} \mathrm{~s}^{-1}$ (i.e., TCs of tropical storm and category- 1 hurricane intensity) and a translation speed between 2 and $6 \mathrm{~m} \mathrm{~s}^{-1}$ and divide the storms into two groups, with storm size being respectively smaller than $340 \mathrm{~km}$ and larger than $360 \mathrm{~km}^{3}$

To unveil the factors responsible for the differences in oceanic response between the SCS and NWP, threedimensional (3D) numerical simulations are carried out using two ocean models: the Price-Weller-Pinkel (PWP) model (Price et al. 1986, 1994) and the Regional Ocean Modeling System (ROMS; Shchepetkin and McWilliams 2005). The PWP model is used to study the TC-induced SST cooling simply because it is computationally inexpensive and thus allows us to test a wide parameter space. ROMS is used to explore the difference in the changes of surface nutrient supply that might be partially responsible for the difference in the surface chlorophyll response, since it is easy to implement inert tracers. A detailed description of the two models and experimental designs is given in appendixes A and $\mathrm{B}$. It is worth noting that although the details of the two models and TC forcing are somewhat different, the model results are qualitatively similar, suggesting that our main conclusions are not sensitive to the model in use.

\section{TC-induced SST response}

\section{a. Regional comparison}

Figure 3a shows the temporal evolution of the composite area-mean SST anomaly induced by TCs of different groups in the NWP. The SST begins to drop a couple of days before the storm passage, usually reaches its minimum 1 day after the passage, and then gradually recovers to its climatologically normal state (e.g., Hart et al. 2007; Price et al. 2008; Dare and McBride 2011; Mei and Pasquero 2012, 2013). The effect of both intensity and translation speed on the magnitude of the TC-induced SST cooling is evident. A weak and fastmoving TC, on average, generates a $0.5^{\circ} \mathrm{C}$ sea surface cooling when averaged over a $3^{\circ} \times 3^{\circ}$ box, and the

\footnotetext{
${ }^{3}$ We omit TCs with a size between 340 and $360 \mathrm{~km}$ in the calculation to better separate the two groups given the uncertainty in the size estimates. Categorizing the two groups with size being respectively smaller and larger than $350 \mathrm{~km}$ produces very similar results.
} 
(a) Tropical northwestern Pacific

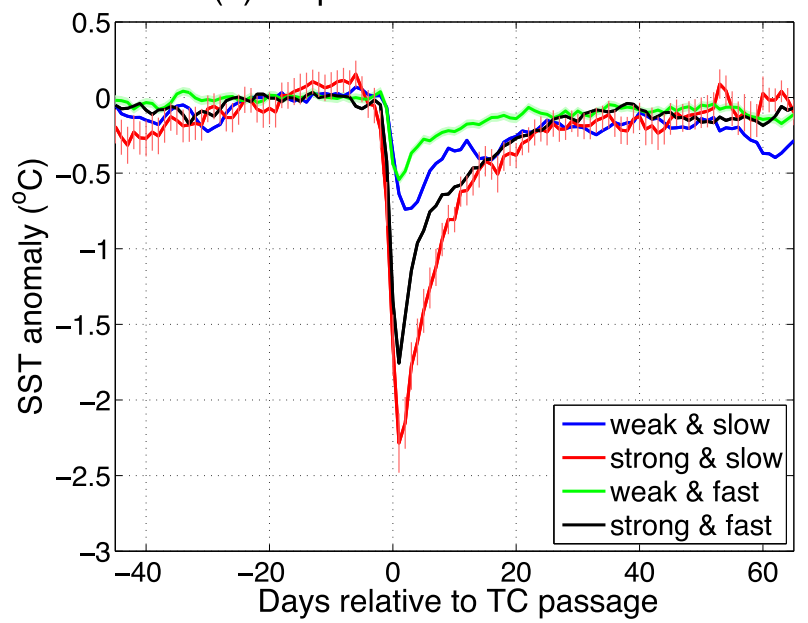

(b) South China Sea

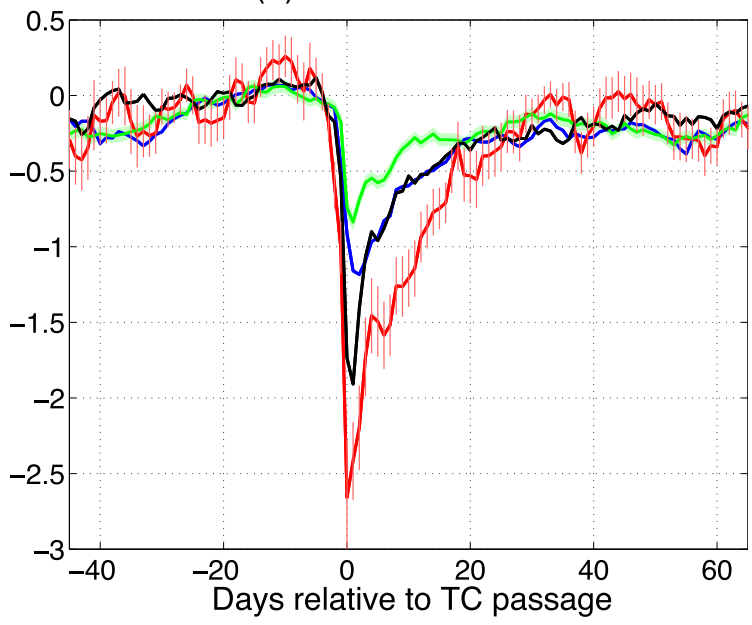

FIG. 3. Temporal evolution of composite area-mean SST anomaly in association with the passage of TCs over the (a) NWP and (b) SCS. Blue, red, green, and black curves, respectively, show the results for weak and slow-moving TCs, strong and slow-moving TCs, weak and fast-moving TCs, and strong and fast-moving TCs (see Table 1). Error bars are calculated as the standard deviation divided by the square root of the effective number of observations (i.e., standard error of the mean) and are shown by the width of the green shading and vertical light red lines for the groups of weak and fast-moving TCs and strong and slow-moving TCs, respectively; the size of the error bar for the other two groups lies between the sizes of these two. The effective number of observations (Table 1) is approximated as the number of observations that are separated by at least $150 \times \sqrt{2} \approx 212 \mathrm{~km}$ in distance or at least 10 days in time.

cooling produced by a weak and slow-moving TC is approximately $50 \%$ stronger. In contrast, a strong and slow-moving $\mathrm{TC}$ induces a cooling of $2.3^{\circ} \mathrm{C}$, more than 4 times that by a weak and fast-moving TC. Note that a considerable fraction of observations are missing during the TC passage because of the adverse effect of heavy rains, particularly for strong TCs [Fig. S1 in the supplemental information; see also a detailed discussion in Mei and Pasquero (2013)]. This may cause a severe underestimate of the TC-induced SST cooling.

Results for TCs over the SCS are displayed in Fig. 3b. For weak and fast-moving, and weak and slow-moving TCs, the produced SST cooling in the SCS is on average around $60 \%$ stronger than that in the NWP. For the other two groups with strong TCs, however, the SST cooling in the SCS is only slightly stronger than that in the NWP (less than 20\%). The discrepancies in the ratio of the SCS versus NWP SST cooling between the two intensity groups can be reconciled by the fact that for the group of strong TCs, the TC intensity in the NWP is around $10 \mathrm{~m} \mathrm{~s}^{-1}$ stronger than in the SCS (Fig. 4). On the contrary, TC intensity is comparable between the NWP and SCS for the group of weak TCs. We then may expect that the TC-induced SST cooling in the SCS can be 50\% (or more) stronger than that in the NWP, if we assume TCs have the same characteristics.

We further explore the dependence of SST response on TC size. As mentioned earlier in section 2, we restrict this analysis to TCs with an intensity between 17.5 and $43.0 \mathrm{~m} \mathrm{~s}^{-1}$ and a translation speed between 2 and $6 \mathrm{~m} \mathrm{~s}^{-1}$.
We then divide the storms into two groups with storm size being respectively smaller than $340 \mathrm{~km}$ and larger than $360 \mathrm{~km}$. Details on averaged TC information are given in Table 2. Figure 5a shows the SST response for the two groups of storms both in the SCS and NWP. In both regions, larger storms tend to produce a stronger cooling, and the cooling induced by large storms is $1.4-1.7$ times

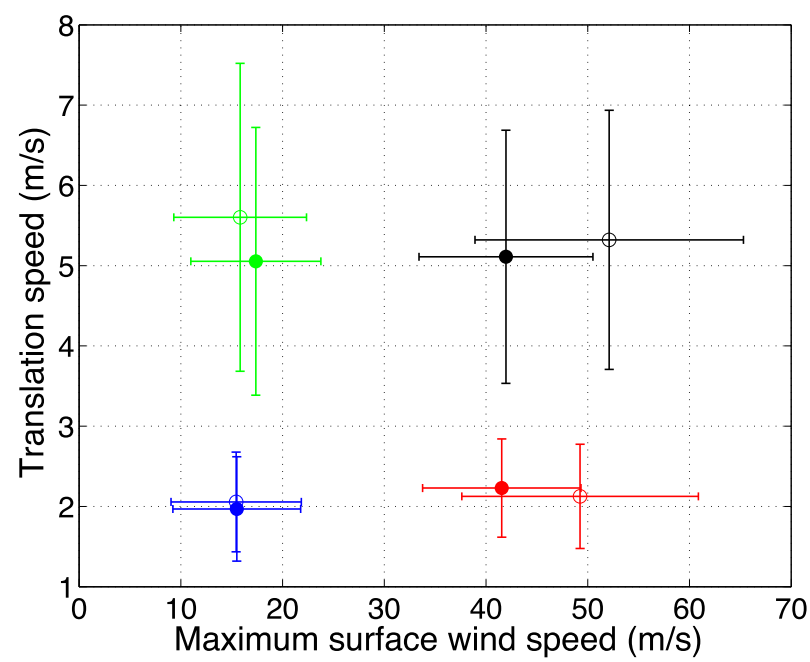

FIG. 4. Mean intensity (measured by the maximum surface wind speed) and translation speed for TCs over the NWP (open circles) and SCS (dots) listed in Table 1. Blue, red, green, and black colors respectively show the results for weak and slow-moving TCs, strong and slow-moving TCs, weak and fast-moving TCs, and strong and fast-moving TCs. The bars show the standard deviation of each individual group. 
TABLE 2. TC groups categorized based on TC size (for TCs with intensity between 17.5 and $43.0 \mathrm{~m} \mathrm{~s}^{-1}$ and translation speed between 2.0 and $6.0 \mathrm{~m} \mathrm{~s}^{-1}$ ). Values for size, intensity, and translation speed are the mean plus or minus the std dev. The numbers below the case number column show the number of 6-h observations, while those in parentheses show the effective number of observations.

\begin{tabular}{lccccc}
\hline \hline \multicolumn{2}{c}{ TC group } & Size $(\mathrm{km})$ & Intensity $\left(\mathrm{m} \mathrm{s}^{-1}\right)$ & Translation speed $\left(\mathrm{m} \mathrm{s}^{-1}\right)$ & Case No. \\
\hline \multirow{2}{*}{ NWP } & Small & $270.16 \pm 48.47$ & $26.35 \pm 6.86$ & $4.16 \pm 1.07$ & $313(146)$ \\
\multirow{3}{*}{ SCS } & Large & $433.10 \pm 62.54$ & $29.42 \pm 7.78$ & $4.04 \pm 1.10$ & $230(107)$ \\
& Small & $272.97 \pm 45.40$ & $26.40 \pm 7.67$ & $4.01 \pm 1.11$ & $298(130)$ \\
& Large & $412.63 \pm 81.96$ & $29.24 \pm 6.36$ & $4.17 \pm 1.04$ & $119(53)$ \\
\hline
\end{tabular}

that by small storms when averaged over a $3^{\circ} \times 3^{\circ}$ box centered at the TC center. For similar TC size, the SST cooling in the SCS is around $50 \%$ stronger than that in the NWP. We would also like to examine the dependence on the ratio between TC size and translation speed (i.e., aspect ratio). But because of the limited sample size from observations, we will address this issue later in this subsection based on numerical results.

The above analyses show that when the TC forcing is identical, the generated SST cooling in the SCS is at least $50 \%$ stronger than in the NWP. This large difference can be primarily attributed to differences in the upper-ocean condition, such as climatological mixed layer depth and stratification in the thermocline, over these two regions. To illustrate this, Figs. $6 \mathrm{a}$ and $6 \mathrm{~b}$ compare the vertical profiles of the climatological temperature and salinity in the NWP and SCS during the typhoon peak season (i.e., July-October). ${ }^{4}$ The mixed layer depth defined according to temperature difference [i.e., the depth where the water temperature is $0.7^{\circ} \mathrm{C}$ lower than the SST; see de Boyer Montégut et al. (2004) for various definitions] is around $30 \mathrm{~m}$ in the SCS and $50 \mathrm{~m}$ in the NWP. The thermal stratification underneath (defined as the vertical temperature gradient between 50- and 100-m depth) in the SCS is nearly 2 times that in the NWP. The stronger vertical gradient in salinity also contributes to a shallower mixed layer in the SCS, but the salinity gradient below 50-m depth (which corresponds to the mixed layer depth in the NWP) is generally comparable between these two regions and thus does not significantly contribute to the stratification difference in the thermocline.

To understand the physical mechanisms for differences in TC-induced SST cooling between the SCS and NWP, we conduct simulations using the PWP model forced by TCs of various intensities and/or translation speeds. Specifically, we run the model with TC translation speed $U_{h}$ varying between 1 and $10 \mathrm{~m} \mathrm{~s}^{-1}$ and with intensity varying between 5 and $80 \mathrm{~m} \mathrm{~s}^{-1}$ in both regions.

\footnotetext{
${ }^{4}$ Note that although in each individual region both temperature and salinity profiles have strong seasonal changes, the contrast between the NWP and SCS appears to be relatively stable (Fig. S2 in the supplemental information).
}

Figure 7 shows the model-simulated SST cooling as a function of both intensity and translation speed using the profiles of temperature and salinity shown in Figs. 6a and $6 \mathrm{~b}$. The model reproduces many observed features shown in Fig. 3. For example, the model results show that for an identical TC, its induced SST cooling is stronger in the SCS than in the NWP. In addition, in both regions, the observed strong dependence of the SST cooling on TC intensity and translation speed is also captured by the model. Note that here we only aim to qualitatively capture the observed features or relationships, instead of reproducing the observed values because of the idealized nature of our simulations.

We also examine the dependence of SST response on TC size and aspect ratio over the two regions using the PWP model by increasing and decreasing the TC size $L$ by $50 \%$. Specifically, the radius of maximum wind (kilometers)/TC size (kilometers) is 27.5/110, 55/220, and $82.5 / 330$, respectively, in the three simulations; the one with 55/220 is the control experiment. Figure 5b shows the TC-induced cooling in the three experiments with a translation speed of $U_{h}=1 \mathrm{~m} \mathrm{~s}^{-1}$; the conclusion is similar for other translation speeds. It is evident that larger TCs produce a stronger cooling averaged over an area of a limited size centered at the storm center when the storm intensity and translation speed are fixed. This is consistent with observational results shown in Fig. 5a. We then proceed to examine the dependence of the cooling on the aspect ratio of storms that is defined as $L / U_{h}$. Figure $5 \mathrm{c}$ shows the results from six experiments with $L / U_{h}$ being

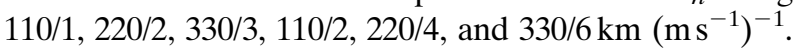
The first three experiments have the same aspect ratio, while the last three experiments have the same ratio, and the former ratio is twice that of the latter. Understandably, TCs of the same aspect ratio generate a similar cooling, and TCs of a larger aspect ratio produce a stronger cooling.

\section{b. Sensitivity to temperature and salinity profiles}

To examine the respective importance of mixed layer depth and stratification in the thermocline for the regional difference in SST cooling, we repeat the simulations (with fixed TC size but varied intensity and translation speed) for the SCS with the vertical profile of 

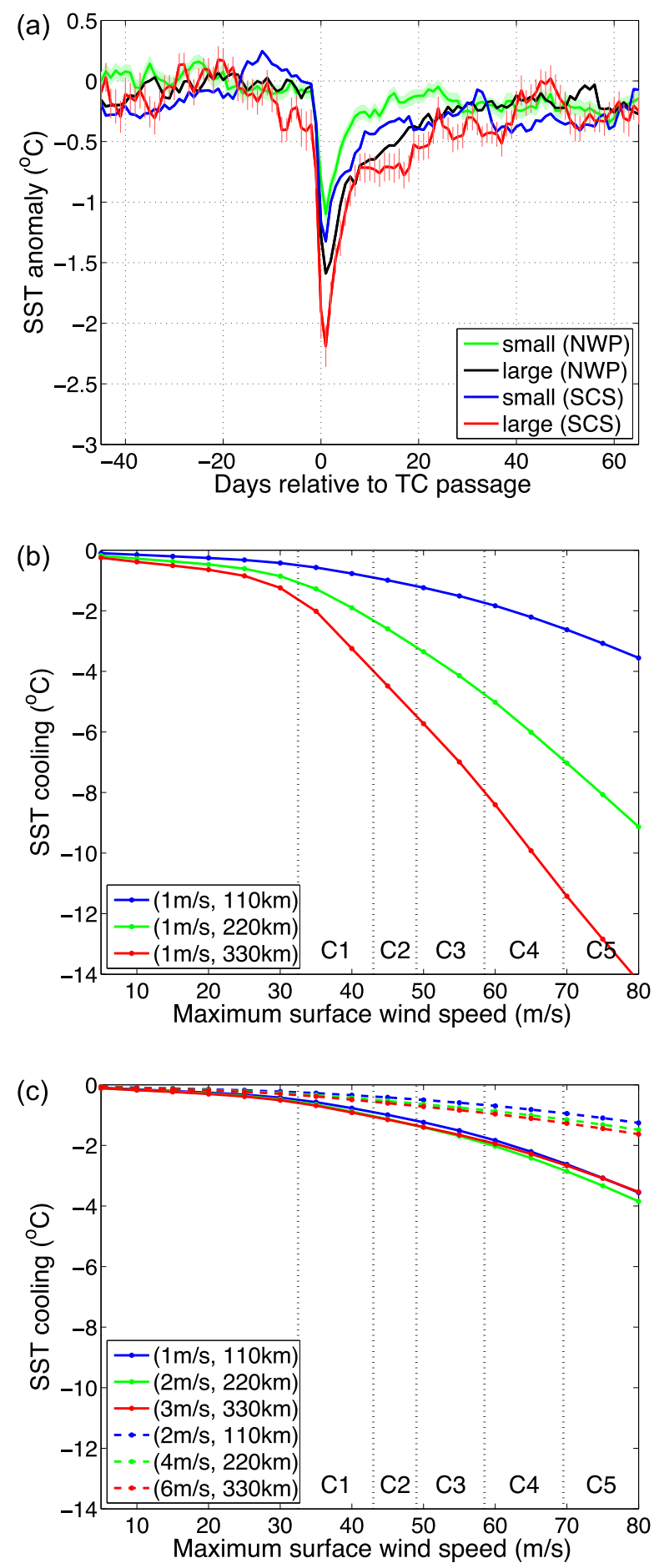

FIG. 5. (a) Temporal evolution of composite area-mean SST anomaly in association with the passage of TCs of different sizes in the NWP and SCS (see Table 2): small TCs in the NWP (green), large TCs in the NWP (black), small TCs in the SCS (blue), and large TCs in the SCS (red). (b) PWP-simulated area-mean SST cooling as a function of TC intensity for TCs of same translation speed $\left(U_{h}=\right.$ $1 \mathrm{~m} \mathrm{~s}^{-1}$ ) but different sizes $L$ over the NWP: $L=110$ (blue), 220 (green), and $330 \mathrm{~km}$ (red). (c) As in (b), but for different combinations of size and translation speed $U_{h}: L / U_{h}=110 / 1$ (blue solid), 220/2 (green solid), 330/3 (red solid), 110/2 (blue dashed), 220/4

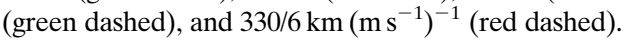

temperature or salinity being modified in the three ways described in appendix A. The first modification is to test the contribution of differences in the vertical salinity gradient to the difference in SST cooling. It turns out that this effect is negligible (Fig. S3 in the supplemental information), despite it acts to slightly reduce the amplitude of the SST cooling because of the stronger vertical gradient in the surface layer of the SCS.

Modification 2 corresponds to an increase of the mixed layer depth in the SCS to $50 \mathrm{~m}$ (i.e., the mixed layer depth in the NWP) without changes in the thermal stratification below the mixed layer (green curve in Fig. 8 a) and modification 3 corresponds to a reduction of the thermal stratification below the mixed layer in the SCS to that in the NWP without changes in the mixed layer depth (black curve in Fig. 8a). Figures $8 \mathrm{~b}$ and $8 \mathrm{c}$ show the results for modifications 2 and 3, with Fig. 8 b for modification 3 and Fig. $8 \mathrm{c}$ for modification 2. Both the increasing prestorm mixed layer depth and reducing vertical temperature gradient in the thermocline can significantly weaken the TC-induced SST cooling. The relative importance of these two effects, however, has a strong dependence on regimes that are defined based on TC intensity and translation speed. For weak and/or fast-moving storms, the shallower prestorm mixed layer depth plays a more important role in producing a stronger cooling in the SCS (cf. the high-intensity end of the three curves with a translation speed of $10 \mathrm{~m} \mathrm{~s}^{-1}$ in Figs. $7 \mathrm{~b}$ and $8 \mathrm{~b}, \mathrm{c})$. This is because for a deeper prestorm mixed layer, more kinetic energy input is needed to initiate the mixing process before the stratification in the thermocline comes into play. This regime can be understood using the simple expressions of post-TC mixed layer depth $h$ and TC-induced SST cooling (SSTA) shown in Mei and Pasquero (2013):

$h=\left(\frac{h_{\mathrm{cml}}^{2}+\sqrt{h_{\mathrm{cml}}^{4}+\frac{16 \mathrm{Ri}\left(\rho_{a} C_{d} V_{s}^{2}\right)^{2}}{N^{2}(\omega-f)^{2} \rho_{o}^{2}}\{1-\cos [(\omega-f) t]\}}}{2}\right)^{1 / 2}$,

and

$$
\operatorname{SSTA}=-\frac{1}{2 h} \Gamma\left(h-h_{\mathrm{cml}}\right)^{2},
$$

where $h_{\mathrm{cml}}$ is the depth of the prestorm mixed layer; $\mathrm{Ri}$ is the bulk Richardson number; $\rho_{a}$ is the air density; $C_{d}$ is the drag coefficient; $V_{s}$ is the surface wind speed; $N$ is the buoyancy frequency; $f$ is Coriolis parameter; $\omega$ is the frequency of the periodic winds; $\rho_{o}$ is seawater density; $t$ is 
(a) Temperature

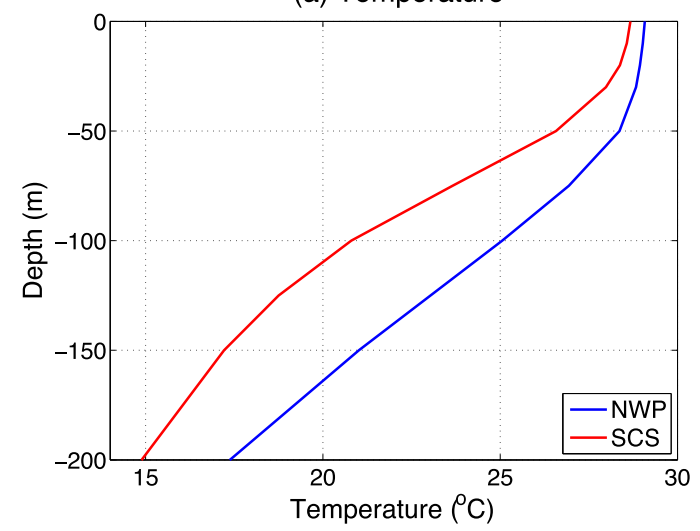

(c) Nitrate

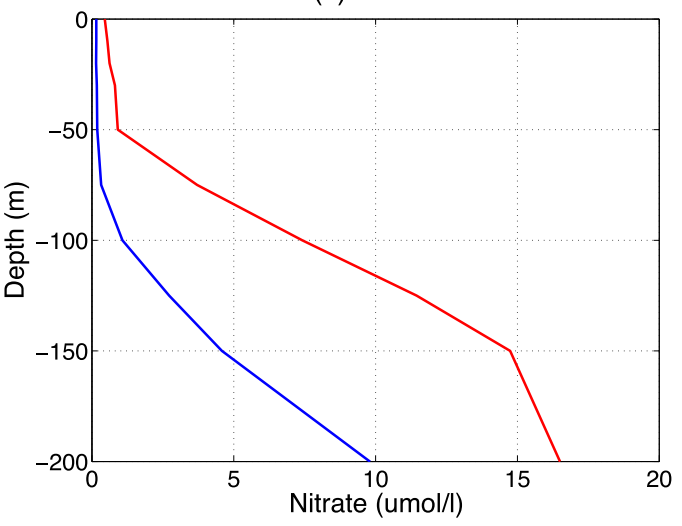

(e) Silicate

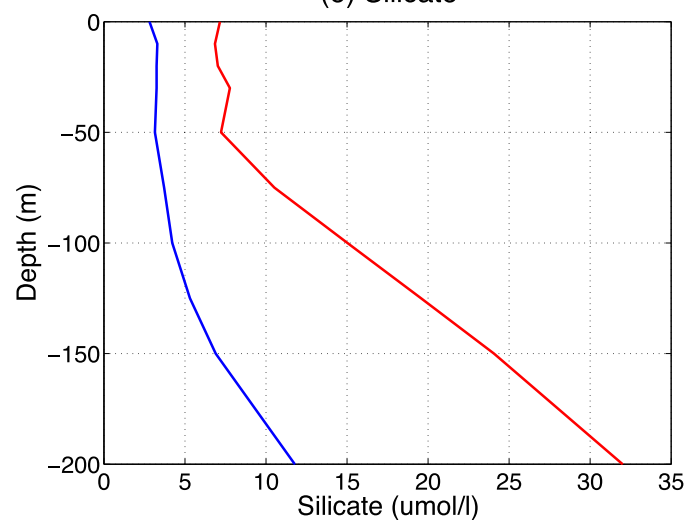

time; and $\Gamma$ is the prestorm vertical temperature gradient below the mixed layer. To illustrate the relationships among $h, h_{\mathrm{cml}}, t$ (which is largely determined by translation speed for a fixed TC size), and $V_{s}$, we apply the Taylor expansion to (1) and assume $t$ and/or $V_{s}$ is extremely small (as we consider a regime of weak and/or fast-moving storms). Using the Taylor series expansion twice (both with $\left.\left\{\operatorname{Ri} \rho_{a}^{2} C_{d}^{2} /\left[N^{2}(\omega-f)^{2} \rho_{o}^{2} h_{\text {coll }}^{4}\right]\right\} V_{s}^{4}\{1-\cos [(\omega-f) t]\} \ll 1\right)$, we get the deepening of the mixed layer due to the storm passage $\Delta h$ as (b) Salinity

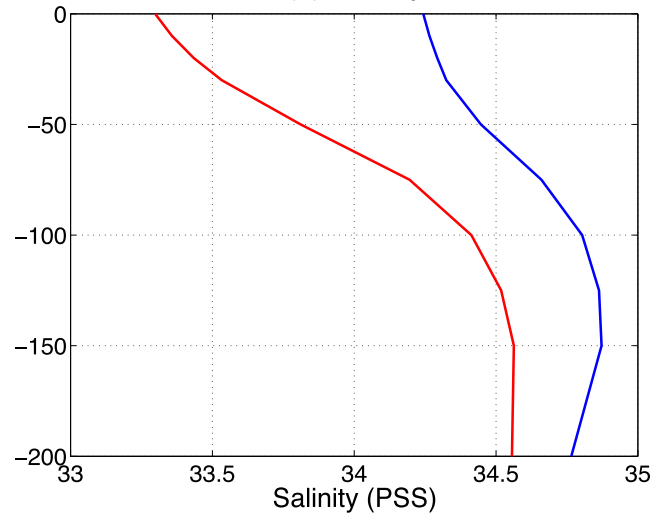

(d) Phosphate

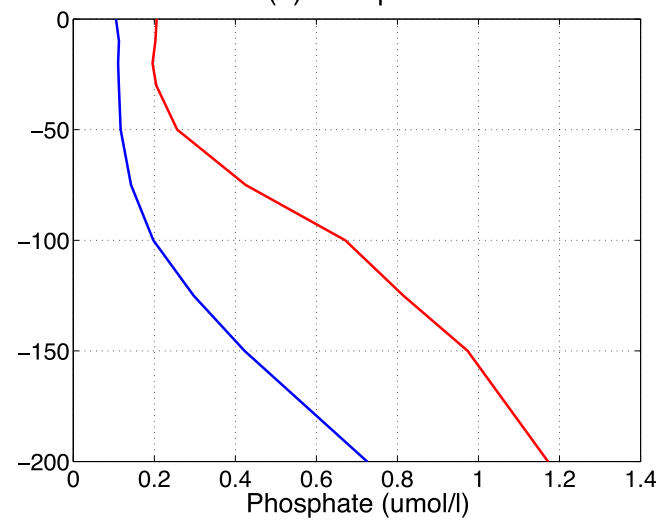

FIG. 6. Climatological July-October mean profiles of (a) temperature, (b) salinity [practical salinity scale (PSS)], and profiles of concentrations $\left(\mu \mathrm{mol}^{-1}\right)$ for (c) nitrate, (d) phosphate, and (e) silicate over the NWP (blue) and SCS (red).

$\Delta h=h-h_{\mathrm{cml}} \approx \frac{2 \mathrm{Ri} \rho_{a}^{2} C_{d}^{2}}{N^{2}(\omega-f)^{2} \rho_{o}^{2}} \frac{\{1-\cos [(\omega-f) t]\} V_{s}^{4}}{h_{\mathrm{cml}}^{3}}$.

It is clear that when $h_{\mathrm{cml}}$ is large, a fast-moving (i.e., small $\{1-\cos [(\omega-f) t]\})$ and/or weak (i.e., small $V_{s}$ ) storm struggles to produce a considerable deepening of the mixed layer $\Delta h$. This, together with the fact that a larger amount of surface warm water needs to be cooled 

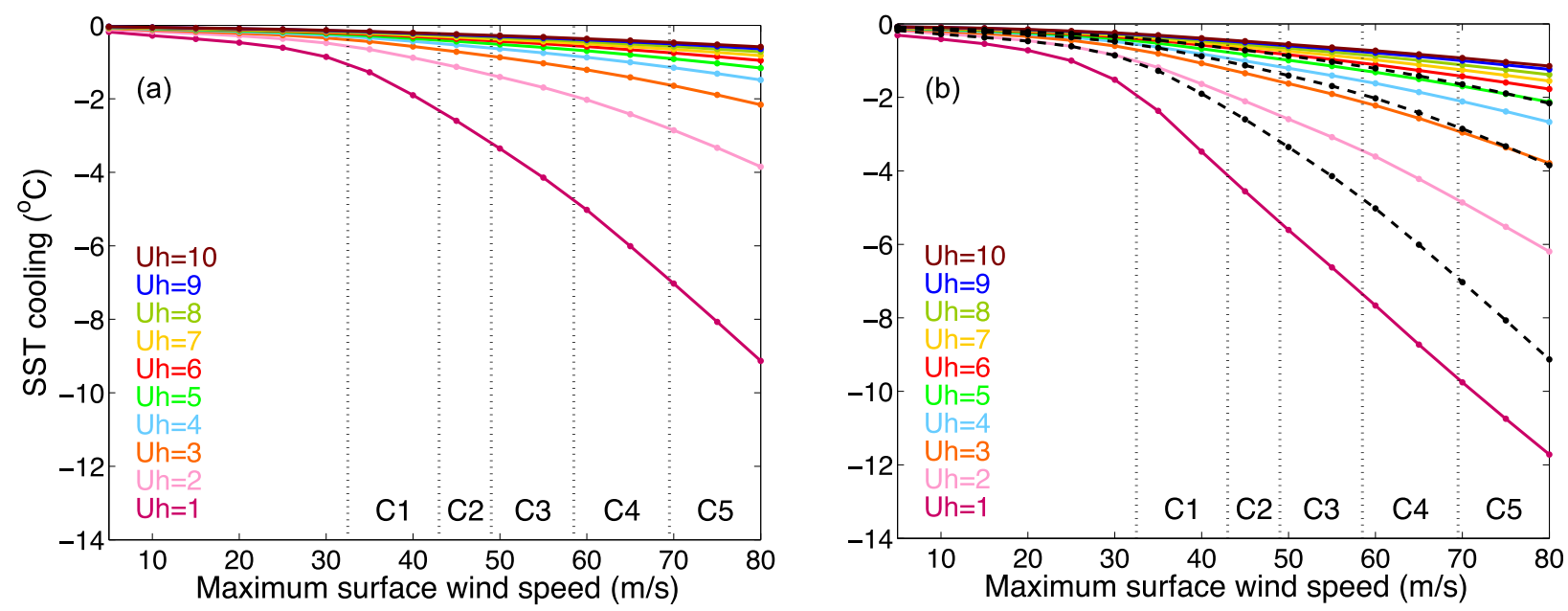

FIG. 7. PWP-simulated area-mean SST cooling as a function of TC intensity for various values of translation speed $U_{h}$ (curves of different colors) over the (a) NWP and (b) SCS. For comparison purposes, the curves for $U_{h}=1,2$, and $3 \mathrm{~m} \mathrm{~s}^{-1}$ in (a) are also shown in (b) as dashed black curves.

down for a deeper mixed layer, makes it difficult to produce SST cooling of a considerable magnitude.

In contrast, when the storm is strong and slow-moving, there is abundant kinetic energy ${ }^{5}$ for mixing the surface warm water with the colder water underneath. Accordingly, the two effects (i.e., increasing prestorm mixed layer depth and reducing thermocline thermal stratification) are comparable (cf. the high-intensity end of the two curves with a translation speed of $1 \mathrm{~m} \mathrm{~s}^{-1}$ in Figs. 8b,c).

Note that here we only discussed two extreme cases: weak and/or fast-moving storms and strong and slowmoving storms. For other cases, such as strong and fastmoving storms and weak and slow-moving storms, the results are located in between. In addition, in the discussion of this subsection we did not consider the effect of TC size. This effect should be similar to that of translation speed, as both of them determine $t$; a large TC size has an equivalent effect as a slow-moving speed, and a small size has an effect equivalent to a fast-moving speed.

\section{TC-induced chlorophyll response}

\section{a. Observed chlorophyll changes}

Figure 9 shows the temporal evolution of the anomaly in chlorophyll concentration with respect to the TC passage for both the SCS and NWP. As the SST, in both

\footnotetext{
${ }^{5}$ The total amount of kinetic energy injected into the ocean by a storm is equal to the energy input rate (i.e., energy input per unit time) times the duration of energy input. A strong storm tends to have a large energy input rate, and a slow-moving storm favors a longer duration of energy input. Thus, a strong and slow-moving storm can lead to very large kinetic energy in the upper ocean.
}

regions chlorophyll responds rather rapidly to the storm passage, with a pronounced enhancement appearing a few days after the passage as the biological response takes time. ${ }^{6}$ And significant differences in the chlorophyll response can be found between the two regions. First, for similar TC forcing, the increase in chlorophyll concentration is around 10 times stronger in the SCS than in the NWP. This is generally consistent with previous findings. Second, although in both regions the chlorophyll response more or less depends on TC intensity and translation speed, the dependence on these TC properties is more prominent in the NWP than in the SCS. One possible explanation for these two observed features is that the local physical and/or biological upper-ocean conditions in the SCS are so favorable that the surface chlorophyll concentration there is sensitive to external forcing and noise, as evidenced by a stronger background variability (such as between days -40 and -20 ) in this region.

An increase in surface chlorophyll content can be primarily attributed to two processes: vertical advection and mixing of chlorophyll from below and new production of chlorophyll as a result of increased surface nutrient supply that is in turn caused by TC-induced vertical mixing. Measurements from a few ocean sites show that a subsurface chlorophyll maximum exists in both the SCS and NWP (e.g., Furuya 1990; Liu et al. 2002). A lack of long-term and large-scale observations of vertical chlorophyll distribution prevents us from an accurate estimate of the contribution by vertical advection and mixing of chlorophyll. A rough estimate

\footnotetext{
${ }^{6}$ Berdalet et al. (1996) showed that chlorophyll can respond to nutrient increases after 2 days.
} 

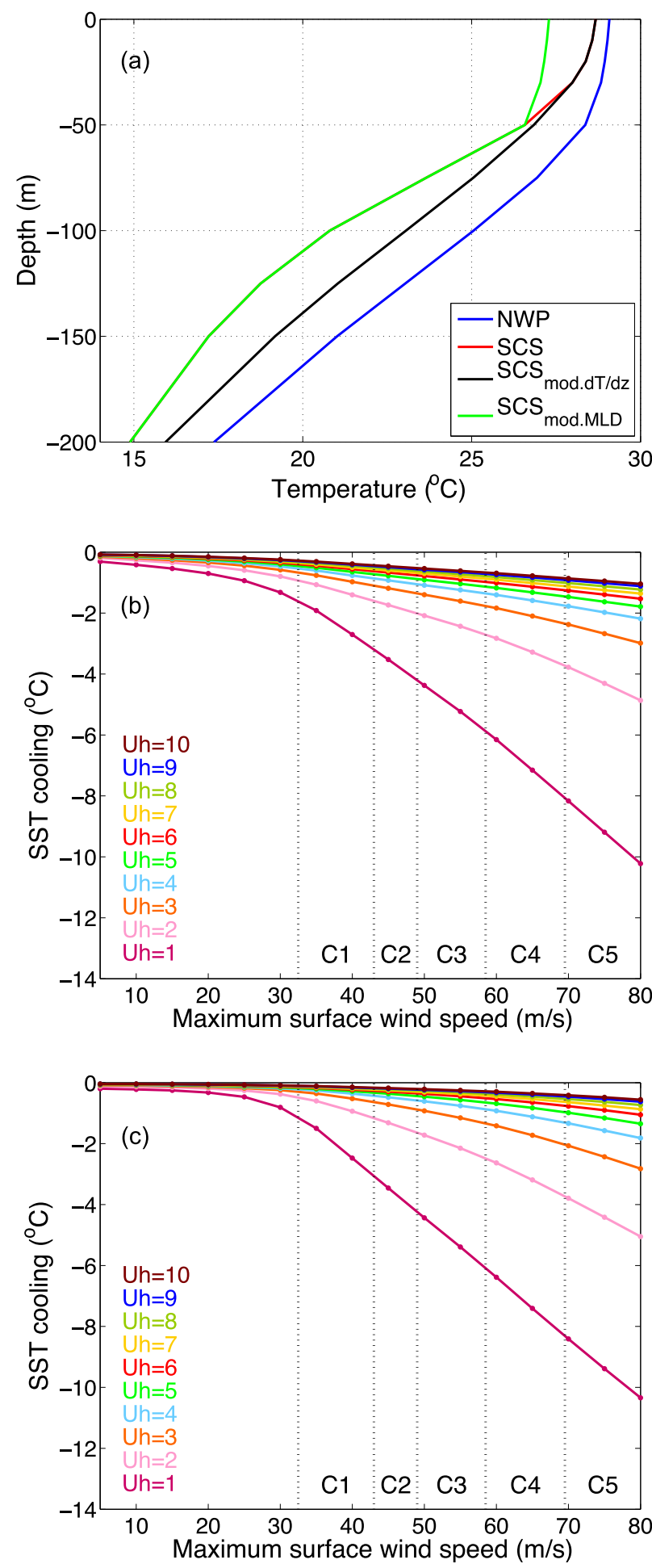

FIG. 8. (a) Climatological July-October mean temperature profiles over the NWP (blue), over the SCS (red), over the SCS but with the thermocline stratification being replaced by the one over the NWP (black) and over the SCS but with the mixed layer having the same shape as the NWP (green). See appendix A for a detailed description. (b),(c) As in Fig. 7b, but with the initial temperature profile [red curve in (a)] being replaced respectively by the black and green curves in (a). using available site measurements (e.g., Fig. 4 in Liu et al. 2002), however, suggests that this process may account for a $20 \%-50 \%$ increase in chlorophyll content, depending on TC features. Such an increase is small compared to the results shown in Fig. 9, which indicate a $40 \%-200 \%$ and $100 \%-225 \%$ increase respectively for the NWP and SCS (the prestorm chlorophyll concentration is around 0.05 and $0.2 \mathrm{mg} \mathrm{m}^{-3}$ for these two regions, respectively). This discrepancy may be largely attributed to the effect of the increased surface nutrient supply, which is examined in next subsection using ROMS.

Before proceeding to understand the underlying mechanisms of these regional differences, we show the vertical profiles of climatological contents of various nutrients in Figs. 6c-e. The nutrients examined here, including nitrate, phosphate, and silicate, exhibit nearly the same features in each individual region but have very different structures between the two regions. For instance, nutrients are rather uniform in the upper $50 \mathrm{~m}$ in the SCS, whereas the uniform layer extends down to a 100-m depth in the NWP. In addition, all nutrients have a stronger vertical gradient below the uniform layer in the SCS than in the NWP.

\section{b. ROMS-simulated changes in surface nutrient content}

Four groups of experiments using ROMS with the nutrients being included as passive tracers are then performed to understand the factors for the regional differences in the changes of surface nutrient supply that are partially responsible for the regional differences in surface chlorophyll response. The four groups differ in the initial temperature and salinity vertical profiles (from the SCS or NWP) and/or nutrient profiles (from the SCS or NWP). Each group consists of four experiments that differ in TC forcing, that is, different intensity $\left(20\right.$ or $\left.50 \mathrm{~m} \mathrm{~s}^{-1}\right)$ and/or translation speed $\left(2\right.$ or $\left.5 \mathrm{~m} \mathrm{~s}^{-1}\right)$.

Before discussing the simulated changes in surface nutrient concentration, we first briefly show the SST cooling simulated by ROMS. Again, here we do not intend to accurately reproduce the observed values because of the idealized nature of our simulations; instead, we pay more attention to relative values. Consistent with observations and PWP model simulations, for identical TC forcing, SST cooling is more than $50 \%$ stronger in the SCS than in the NWP (cf. the first and third columns in Fig. 10a). And in both regions, the amplitude of the cooling strongly depends on both TC intensity and translation speed.

Figure $10 \mathrm{~b}$ shows the ROMS-simulated response in nitrate concentration from experiments with different initial conditions and/or TC forcing; results are basically similar for phosphate and silicate. One prominent feature is that weak TCs are barely able to generate a significant response in surface nutrient concentration over 
(a) Tropical northwestern Pacific

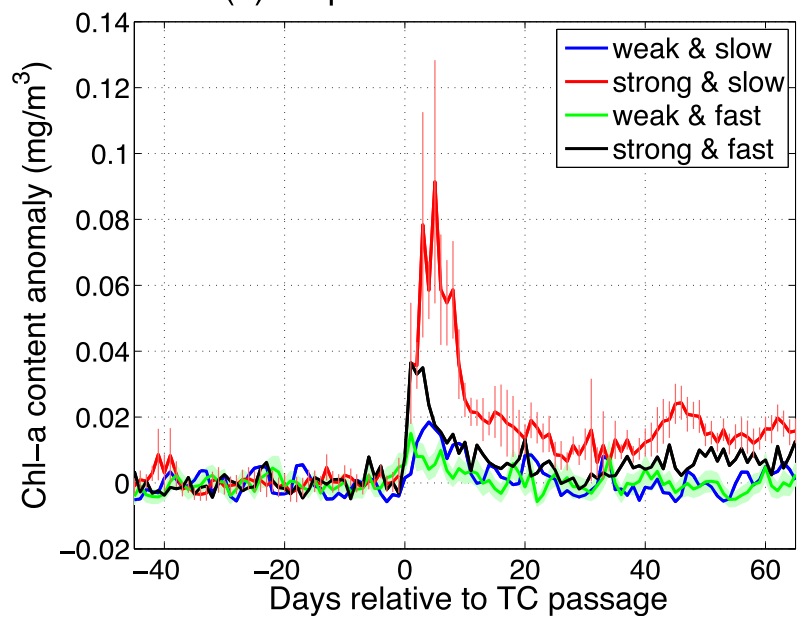

(b) South China Sea

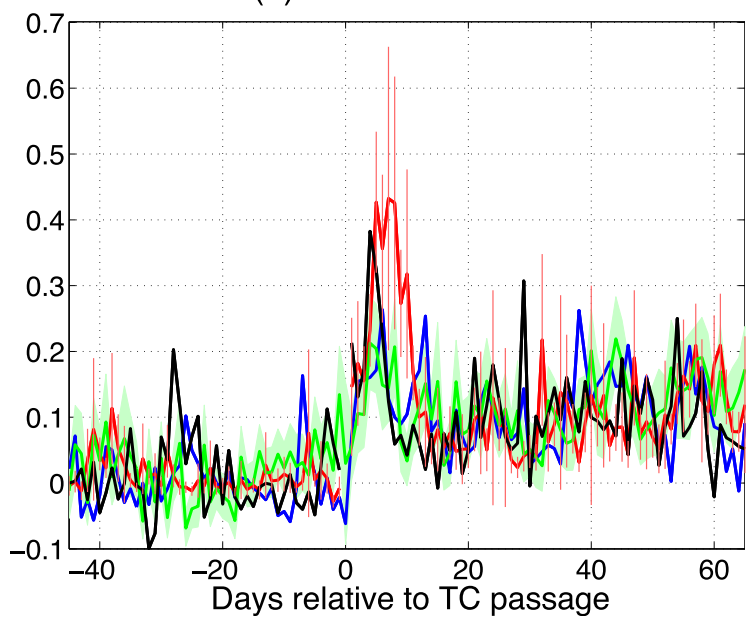

FIG. 9. As in Fig. 3, but for the anomaly in composite area-mean chlorophyll concentration. Note the different $y$-axis scales between (a) and (b).

the NWP because of the very deep nutricline. This is different from the TC-induced SST cooling but is generally consistent with the modest changes in chlorophyll for weak storms in observations.

The most marked feature, however, is that, for identical TC forcing, the ratio of changes in nutrient concentration in the SCS to those in the NWP varies between three and five (cf. the first and third columns in Fig. 10b), which is larger than the ratio for SST cooling (slightly greater than 1.5 ; cf. the first and third columns

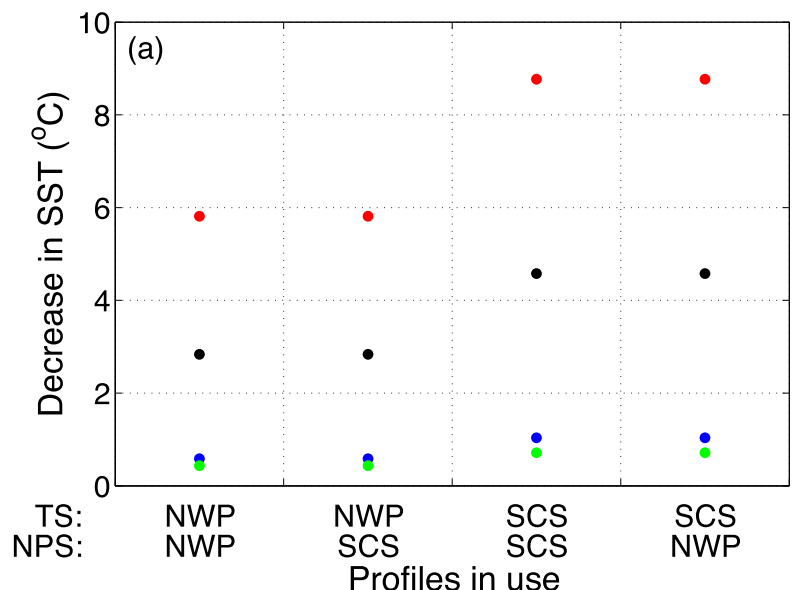

- Weak \& slow

- Strong \& slow in Fig. 10a). This is broadly in line with observations. A comparison between experiments initialized with different temperature and salinity profiles or different nutrient profiles shows that such a large difference between the two regions is because of the difference in nutrient profiles (both the depth of the upper uniform layer and vertical gradient in the nutricline; cf. the first and second columns in Fig. 10b); the weaker stratification set up by temperature and salinity in the NWP actually favors a slightly larger increase in surface nutrient

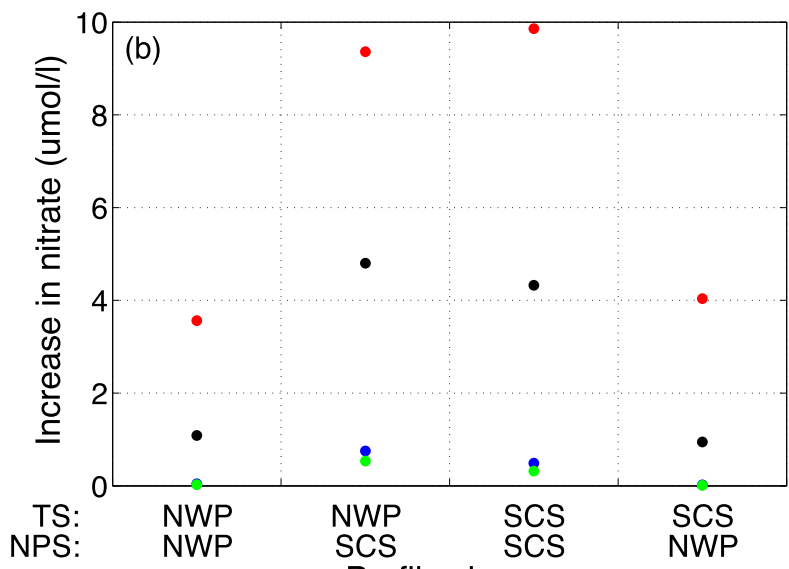

Profiles in use

- Weak \& fast

- Strong \& fast

FIG. 10. ROMS-simulated amplitude of (a) area-mean SST cooling and of (b) increase in area-mean nitrate concentration induced by TCs of different characteristics [blue indicates weak and slow moving (intensity $V_{s}=20 \mathrm{~m} \mathrm{~s}^{-1}$ and translation speed $U_{h}=2 \mathrm{~m} \mathrm{~s}^{-1}$ ); red indicates strong and slow moving $\left(V_{s}=50 \mathrm{~m} \mathrm{~s}^{-1}\right.$ and $\left.U_{h}=2 \mathrm{~m} \mathrm{~s}^{-1}\right)$; green indicates weak and fast moving $\left(V_{s}=20 \mathrm{~m} \mathrm{~s}\right.$ and $U_{h}=$ $\left.5 \mathrm{~m} \mathrm{~s}^{-1}\right)$; and black indicates strong and fast moving $\left(V_{s}=50 \mathrm{~m} \mathrm{~s}^{-1}\right.$ and $\left.\left.U_{h}=5 \mathrm{~m} \mathrm{~s}^{-1}\right)\right]$ under different initial conditions of temperature and salinity as well as of nutrient concentrations. The terminology TS:NWP and TS:SCS indicates that the model is initialized with temperature and salinity profiles of the NWP and SCS, respectively; and NPS:NWP and NPS:SCS indicates that the model is initialized with nutrient (including nitrate, phosphate, and silicate) profiles of the NWP and SCS, respectively. 
TABLE 3. VGPM-estimated primary production increase associated with the passage of TCs of different characteristics over two weeks $\left(\mathrm{mg} \mathrm{C} \mathrm{m}^{-2}\right)$. Values for NWP and SCS are the mean plus or minus the standard error of the mean.

\begin{tabular}{lcr}
\hline \multicolumn{1}{c}{ TC group } & NWP & \multicolumn{1}{c}{ SCS } \\
\hline Weak and slow & $210.61 \pm 129.87$ & $1595.54 \pm 271.55$ \\
Strong and slow & $1148.75 \pm 202.36$ & $4301.19 \pm 932.01$ \\
Weak and fast & $51.18 \pm 26.40$ & $776.34 \pm 144.02$ \\
Strong and fast & $415.80 \pm 44.36$ & $1588.95 \pm 273.60$ \\
\hline
\end{tabular}

concentration, except for strong, slow-moving TCs (cf. the second and third columns in Fig. 10b).

It is worth noting that the ratio of the surface nutrient concentration change in the model of the SCS to that in the model of the NWP is still smaller than that for chlorophyll in observations (i.e., 3-5 versus 10 ). This discrepancy may be because of the following reasons: 1) nutrient availability is one of the factors limiting phytoplankton growth in the ocean, but it is not the only one, and light availability as well as trophic interactions can also play an important role; 2) changes in surface nutrients produced by local processes may only partially explain changes in surface chlorophyll concentration, and other processes not included in the model, such as the vertical advection and mixing of subsurface chlorophyll-rich water to the surface, may also greatly contribute to the surface chlorophyll changes; 3) the observations may not be that accurate owing to the contamination of satellite signals by clouds and precipitation; and 4) our simulations are very idealized regarding initialization, forcing, and boundary conditions with many processes not being included or well represented (e.g., missing some of the air-sea interactions and deficiencies in modeled vertical mixing processes). Further exploration using a coupled ocean-atmosphere-wave model with both physical and biogeochemical processes included may be helpful.

\section{c. Estimation of possible changes in primary production}

We further estimate the changes in primary production associated with the TC passage using the vertically generalized production model (VGPM; Behrenfeld and Falkowski 1997) together with satellitederived chlorophyll concentration and SST data used in the above calculations. We first apply the VGPM to SST and chlorophyll for each TC location and then compute the composites. The photosynthetically available radiation (PAR) value in the month when the TC occurred is used for each specific TC location; the PAR data are from the NASA OceanColor data website (http:// oceandata.sci.gsfc.nasa.gov/MODISA/Mapped/Monthly/ $9 \mathrm{~km} /$ ). Table 3 lists the increase in primary production over a two-week period right after the storm passage for TCs of different features. Its dependence on TC characteristics is generally consistent with the dependency of chlorophyll concentration, with strong and/or slowmoving TCs generating a strong increase in primary production. For identical TC forcing, the primary production increase in the SCS is 5-10 times that in the NWP.

We then compute the total annual primary production increase associated with the TC passage over these two regions. The effective number of boxes (which have a size of $3^{\circ} \times 3^{\circ}$ and are used in estimating the area-mean change in primary production for each TC observation) is counted using one of the following two criteria: 1) the distance between the two observations is longer than $150 \times \sqrt{2} \approx 212 \mathrm{~km}$, and 2) the separation between their occurrence is longer than 10 days. The first criterion aims to avoid the overlapping of area in calculation, and the use of the second one is because the increase in primary production quickly drops after 10 days following the TC passage (not shown). The total annual primary production increase is estimated to be $6.4 \pm 0.4 \times 10^{12}$ and $2.2 \pm 0.2 \times 10^{12} \mathrm{gC}$, respectively, for the SCS and NWP. The latter value is broadly in line with the estimate by Lin (2012) for the western North Pacific subtropical ocean in 2003. This suggests that although the TC activity integrated over time in the SCS is much weaker than in the NWP, the induced carbon uptake in the former region is nearly 3 times that in the latter.

As a caveat, part of the satellite-observed TC-induced increase in surface chlorophyll concentration may be due to the dilution of the preexisting subsurface chlorophyll maximum via vertical advection and mixing. This component in reality may not lead to new primary production (instead it only redistributes primary production vertically). Thus, the calculation of primary production changes based on the VGPM using SST and satellite-derived chlorophyll concentration may overestimate TC-induced primary production increase. On the other hand, the satellite measurements cannot capture TC-induced subsurface chlorophyll bloom that has been documented by cruise survey data (e.g., Ye et al. 2013). The subsurface bloom is observed to be even stronger and longer lasting than the surface bloom in case studies. The VGPM does not consider this contribution and thus may considerably underestimate TC-induced new primary production. These two contributions oppose each other, and their quantification is not feasible at the current stage because the needed pre- and post-TC in situ profile measurements are generally unavailable (except for a few cases). Further in situ research is needed to resolve this important issue.

\section{Summary and conclusions}

This study has examined the sea surface temperature (SST) and chlorophyll response to tropical cyclones (TCs) over the South China Sea (SCS) and tropical 
northwest Pacific Ocean (NWP) between 1997 and 2013 using satellite-derived SST and chlorophyll data and TC best-track data. Specifically, we have performed composite analysis conditioned on TC characteristics to investigate the dependence of TC-induced ocean response on TC intensity, translation speed, and/or size. We have also compared the differences in the response between the two regions and sought to understand the controlling factors using three-dimensional (3D) ocean model simulations.

In both the SCS and NWP, TC-generated SST cooling strongly depends on TC intensity, translation speed, and size: stronger, slower-moving, and/or larger TCs tend to produce stronger SST cooling. For the same TC forcing, the SST cooling significantly differs between these two regions. Specifically, the cooling in the SCS is more than 1.5 times that in the NWP. This can be attributed to different upper-ocean states-the mixed layer is shallower and the thermal stratification in the thermocline is stronger in the SCS than in the NWP-which in turn are primarily due to the sloping thermocline that is in approximate geostrophic balance with the Kuroshio. The different amplitude of TC-induced cooling may be partially responsible for the observation that TCs in the SCS on average are weaker than in the NWP. ${ }^{7}$

A 3D Price-Weller-Pinkel (PWP) model is then employed to identify the main physical mechanisms responsible for the regional difference in SST cooling. The model results reveal that for weak and/or fast-moving storms the shallower mixed layer is the dominant factor. In contrast, when a TC is strong and moves slowly, the observed stronger cooling in the SCS is nearly equally contributed by the shallower mixed layer and stronger thermal stratification underneath. The effect of difference in stratification associated with salinity is negligible.

Similar to the SST response, TC-induced increase in surface chlorophyll concentration, which lags the SST cooling by a few days, also exhibits strong dependence on TC characteristics and significantly differs between the SCS and NWP. A larger increase in chlorophyll concentration can be observed after the passage of a stronger and/or slower-moving TC. The dependence on TC characteristics appears to be more prominent in the NWP than in the SCS. The response in chlorophyll concentration in the SCS, however, is nearly 10 times stronger than in the NWP, when subject to the same TC forcing. These relationships also apply to the changes in primary production, as the concurrent decreasing SST

\footnotetext{
${ }^{7}$ The TC-induced SST cooling can negatively feed back onto the TC intensity by diminishing the sea to air heat flux-the energy source of TC development. Thus, a stronger cooling tends to have a stronger negative influence on TC intensity (e.g., Mei et al. 2012).
}

[which reduces the $P_{\mathrm{opt}}^{B}$ parameter in the vertically generalized production model (VGPM); see Behrenfeld and Falkowski (1997) for details] does not affect the net primary production and the increase in chlorophyll dominates. The VGPM-estimated, annually cumulative increase in primary production associated with the TC passage in the SCS is nearly 3 times that in the NWP, although the TC activity integrated over time is much weaker in the former region.

The observed response of chlorophyll concentration is further understood using simulations based on the Regional Ocean Modeling Systems (ROMS). Observed climatological profiles of silicate, nitrate, and phosphate during the TC peak season are included as the model initial conditions and serve as inert tracers to track the spatiotemporal evolution of nutrients. The model can well reproduce the observed features in SST cooling, such as the cooling in the SCS being 1.5 times that in the NWP for identical TC forcing. By comparing experiments initialized with different temperature and salinity and/or nutrient profiles, we show that the stronger chlorophyll increase in the SCS is partially due to both the shallower nutricline and stronger vertical nutrient gradient. The initial vertical distribution of chlorophyll concentration may also contribute through vertical advection and mixing, which has not been examined here. The effect of upper-ocean density stratification on the nutrient response by modulating TC-induced mixing is negligible, with the stratification in the NWP actually being generally more favorable for producing a stronger surface nutrient response.

The results presented in this study provide a climatological perspective of the TC-induced response in SST and surface chlorophyll concentration in the SCS and NWP, serving as the reference for case studies over these two regions. It should be kept in mind that here the response is evaluated as an average over a fairly large area (i.e., $3^{\circ} \times 3^{\circ}$ ) and for many cases and thus can be significantly weaker than the local maximum response and/or the response in an extreme case [such as the cooling generated by Typhoon Kai-Tak (2000) in the SCS]. Our results may also apply to other regions with strong geostrophic currents, such as across the Gulf Stream in both the tropics and midlatitudes and across the Kuroshio in the East China Sea.

The identified dependence of TC-induced oceanic (physical, biological, and biogeochemical) responses on upper-ocean thermal stratification may have important implications on interannual and longer time scales and within the context of paleoclimate and climate change. For example, Tseng et al. (2009) and Liu et al. (2013) recently showed that the state of ENSO can modulate the strength of chlorophyll response to wind forcing in the northern SCS. La Niña conditions generally lead to a 
deepened thermocline in the SCS, which in turn weakens the efficiency of wind-driven nutrient pumping (Liu et al. 2013). In addition, in a warming climate the ocean will experience stronger warming in the surface than the subsurface (e.g., Capotondi et al. 2012; Long et al. 2014). These changes strengthen the thermal gradient in the upper ocean and thereby are expected to affect TCinduced SST response. The changes in mixed layer depth may also modulate the nutricline and affect TC-generated biological and biogeochemical response. Given the regional difference in the ocean response to TC forcing, it is of great interest to examine in which region the TCinduced ocean response is more sensitive to upper-ocean state changes on interannual time scales (e.g., Chao et al. 1996; Fang et al. 2006) and under global warming.

Some other open questions are also left for future studies. First, the ratio of simulated changes in surface nutrient concentration between the SCS and NWP is only half of the ratio of observed changes in surface chlorophyll concentration (i.e., 3-5 versus 10 ). It is unclear whether this is due to the exclusion of vertical advection and mixing of subsurface chlorophyll to the surface, inaccuracy in satellite retrieval products (e.g., because of the contamination of satellite signals by clouds), inaccuracy in model simulations (e.g., because of the deficiencies in parameterization of mixing), or complicated biological processes in reality. A fully coupled oceanatmosphere-wave model including both physical and biogeochemical processes is desirable. Second, research is warranted to quantify how much of the difference in average TC intensity between the SCS and NWP can be explained by the difference in TC-induced SST cooling.

Acknowledgments. This work was supported by NSF Grant AGS-1305719 and NOAA Grant NA13OAR4310092. We thank Prof. Kerry Emanuel for sharing the compiled tropical cyclone best-track data. And we thank the editor and the anonymous reviewers for their comments, which greatly helped improve the manuscript. TMI data are produced by Remote Sensing Systems and sponsored by the NASA Earth Science MEaSUREs DISCOVER Project. Data are available online (www.remss.com). We also thank the MODIS Science Team and Processing team for producing MODIS data.

\section{APPENDIX A}

\section{Simulations Based on the PWP Model}

The three-dimensional PWP ocean model (Price et al. 1986, 1994) is employed to study the TC-induced SST cooling and its dependency. The model solves for the wind-driven, baroclinic ocean response, including a treatment of turbulent vertical mixing in the upper ocean. The model domain has a size of $450 \mathrm{~km}$ (in the cross-track direction) by $460 \mathrm{~km}$ (in the along-track direction) with a 5-km horizontal resolution. The vertical resolution is $5 \mathrm{~m}$ within the upper $100 \mathrm{~m}$ and increases to $10 \mathrm{~m}$ for the depth between 100 and $200 \mathrm{~m}$ and then to $50 \mathrm{~m}$ for greater depths down to $1000 \mathrm{~m}$. Each model grid point is initialized with the same climatological temperature and salinity vertical profiles averaged between July and October (Figs. 6a,b), and thus the ocean initial condition is horizontally homogeneous over the whole domain. In the simulation, the TC is moving within the domain at a constant translation speed $U_{h}$. A maximum wind speed, radius of maximum wind, and $U_{h}$ are required to characterize the TC in the PWP model. Note that the intensity and structure of the TC do not change during the integration. The drag coefficient $C_{d}$ in use is based on Powell et al. (2003).

To examine the respective importance of mixed layer depth and stratification in the thermocline for the difference in TC-induced SST cooling between the SCS and NWP, we modify the vertical profile of temperature or salinity in the SCS using that of the NWP in the following three ways and then repeat the simulations for the SCS: 1) We replace the salinity profile in the SCS with that in the NWP (both are shown in Fig. 6b) in order to test the contribution of salinitydetermined density stratification difference to the difference in SST cooling. 2) The mixed layer depth largely determines how much surface warm water needs to be cooled down and thus plays an important role in shaping the amplitude of the SST cooling. The mixed layer depth defined only using the temperature profile is $\sim 50 \mathrm{~m}$ in the NWP and $\sim 30 \mathrm{~m}$ in the SCS. To quantify the contribution of the mixed layer depth to the regional difference in the TC-induced SST cooling, we set the mixed layer depth in the SCS to be that in the NWP by simply replacing the shape of the vertical temperature profile above $50 \mathrm{~m}$ in the SCS with that in the NWP (green curve in Fig. 8a; the temperatures below $50 \mathrm{~m}$ are unchanged). 3) In addition to mixed layer depth, thermal stratification below the mixed layer greatly shapes how much surface cooling a TC can produce, particularly for strong or slow-moving storms that can generate vigorous mixing to a great depth. Figure 6 a shows that the subsurface vertical temperature gradient is larger than $0.1^{\circ} \mathrm{Cm}^{-1}$ in the SCS, around 2 times that in the NWP. To determine the effect of such a large difference in subsurface thermal stratification, we simply replace the shape of the temperature profile below mixed layer in the SCS with that in the NWP (black curve in Fig. 8a). 


\section{APPENDIX B}

\section{Simulations Based on ROMS}

We run ROMS in an idealized channel configuration on a $\beta$ plane, forced by TC-like wind stress. The domain is centered at $15^{\circ} \mathrm{N}$ in the meridional direction $\left(f=3.76 \times 10^{-5} \mathrm{~s}^{-1}\right.$ and $\left.\beta=2.205 \times 10^{-11} \mathrm{~s}^{-1} \mathrm{~m}^{-1}\right)$ and has a size of $4960 \mathrm{~km} \times 6640 \mathrm{~km} \times 5000 \mathrm{~m}\left(L_{x} \times L_{y} \times H\right)$, using periodic east-west lateral boundary conditions and wall boundaries at the northern and southern edges. The horizontal resolution is $10 \mathrm{~km}$, and there are 100 unequally spaced $\sigma$ layers in the vertical with 20 layers in the upper $100 \mathrm{~m}$. Each simulation is 10 days long, using a time step of $300 \mathrm{~s}$. Third-order upstream-bias horizontal advection and harmonic horizontal mixing are used for temperature, salinity, and momentum. Fourth-order, centered, vertical advection is used for temperature and salinity. The nonlocal $K$-profile parameterization scheme (KPP; Large et al. 1994) is chosen to parameterize the vertical turbulent mixing. Note that the mixing parameterization schemes always have systematic biases relative to the observations in representing turbulent fluxes that are crucial for vertical heat and nutrient transport. Using different schemes can lead to significant differences in the amplitude of TC-induced SST cooling (e.g., Walsh et al. 2010). But qualitative conclusions are not significantly altered by the usage of a specific scheme.

The model ocean is initially at rest and is initialized with horizontally uniform fields of temperature, salinity, and nutrients shown in Fig. 6. During the integration, the model ocean is only subjected to wind forcing; shortwave radiation, longwave radiation, and air-sea turbulent heat fluxes are not included. The lack of heat fluxes should not significantly affect the main results of this study according to Morey et al. (2006), although the detailed numbers may differ. The surface wind field $V_{s}$ associated with a TC is expressed as a modified Rankine vortex model:

$$
V_{s}= \begin{cases}V_{\max } \frac{r}{r_{\max }} & \text { for } \quad r \leq r_{\max } \\ V_{\max }\left(\frac{r_{\max }}{r}\right)^{a} & \text { for } \quad r>r_{\max }\end{cases}
$$

where $r$ is the distance from the storm center; $r_{\max }$ is the radius of maximum wind speed; $V_{\max }$ is the wind speed at $r_{\max }$; and $a$ is a shape parameter. In our simulation, $r_{\max }$ is $50 \mathrm{~km}$, and $a$ is 0.6 . In nature, the TC in the study area (i.e., the SCS and NWP) generally moves at a speed $U_{h}$ in the westward-to-northwestward direction, with $U_{h}$ being largely determined by environmental flows. Thus, we add uniform easterly winds (i.e., the large-scale environmental flow) with an amplitude of $U_{h}$ onto the symmetric TC-like vortex. The added easterly environmental flow respectively strengthens and weakens the winds on the northern and southern part of the TC, producing an asymmetry in the wind forcing near the TC. To avoid large-scale upwelling and downwelling in the simulations, the addition of environmental flow only applies within a circle with a radius of $1000 \mathrm{~km}$ centered at the TC center. The drag coefficient used in the calculations of wind stress is adopted from Walsh et al. (2010, see the red curves in their Fig. 3); we also ran simulations using drag coefficient from Donelan et al. (2004) that levels off for wind speed above $33 \mathrm{~m} \mathrm{~s}^{-1}$ and obtained very similar results. The idealized storm moves from the east to the west at $U_{h}$.

\section{REFERENCES}

Behrenfeld, M. J., and P. G. Falkowski, 1997: Photosynthetic rates derived from satellite-based chlorophyll concentration. Limnol. Oceanogr., 42, 1-20, doi:10.4319/lo.1997.42.1.0001.

Bell, M. M., and M. T. Montgomery, 2008: Observed structure, evolution, and potential intensity of category 5 Hurricane Isabel (2003) from 12 to 14 September. Mon. Wea. Rev., 136, 2023-2046, doi:10.1175/2007MWR1858.1.

Bender, M. A., and I. Ginis, 2000: Real-case simulations of hurricaneocean interaction using a high-resolution coupled model: Effects on hurricane intensity. Mon. Wea. Rev., 128, 917-946, doi:10.1175/1520-0493(2000)128<0917:RCSOHO>2.0.CO;2.

Berdalet, E., C. Marrasé, M. Estrada, L. Arin, and M. L. MacLean, 1996: Microbial community responses to nitrogen- and phosphorus-deficient nutrient inputs: Microplankton dynamics and biochemical characterization. J. Plankton Res., 18, 1627-1641, doi:10.1093/plankt/18.9.1627.

Brand, S., 1971: The effects on a tropical cyclone of cooler surface waters due to upwelling and mixing produced by a prior tropical cyclone. J. Appl. Meteor., 10, 865-874, doi:10.1175/ 1520-0450(1971)010<0865:TEOATC $>2.0 . C O ; 2$.

Capotondi, A., M. A. Alexander, N. A. Bond, E. N. Curchitser, and J. D. Scott, 2012: Enhanced upper ocean stratification with climate change in the CMIP3 models. J. Geophys. Res., 117, C04031, doi:10.1029/2011JC007409.

Chao, S.-Y., P.-T. Shaw, and S. Y. Wu, 1996: El Niño modulation of the South China Sea circulation. Prog. Oceanogr., 38, 51-93, doi:10.1016/S0079-6611(96)00010-9.

Chiang, T.-L., C.-R. Wu, and L.-Y. Oey, 2011: Typhoon Kai-Tak: An ocean's perfect storm. J. Phys. Oceanogr., 41, 221-233, doi:10.1175/2010JPO4518.1.

Chu, J.-H., C. R. Sampson, A. S. Levine, and E. Fukada, 2002: The Joint Typhoon Warning Center tropical cyclone besttracks, 1945-2000. Tech. Rep. NRL/MR/7540-02-16, U.S. Naval Research Laboratory, Washington, DC. [Available online at www.usno.navy.mil/NOOC/nmfc-ph/RSS/jtwc/ best_tracks/.]

Chu, P. C., J. M. Veneziano, C. Fan, M. J. Carron, and W. T. Liu, 2000: Response of the South China Sea to Tropical Cyclone Ernie 1996. J. Geophys. Res., 105, 13 991-14 009, doi:10.1029/ 2000JC900035. 
Cione, J. J., and E. W. Uhlhorn, 2003: Sea surface temperature variability in hurricanes: Implications with respect to intensity change. Mon. Wea. Rev., 131, 1783-1796, doi:10.1175//2562.1.

Dare, R. A., and J. L. McBride, 2011: Sea surface temperature response to tropical cyclones. Mon. Wea. Rev., 139, 3798-3808, doi:10.1175/MWR-D-10-05019.1.

de Boyer Montégut, C., G. Madec, A. S. Fischer, A. Lazar, and D. Iudicone, 2004: Mixed layer depth over the global ocean: An examination of profile data and a profile-based climatology. J. Geophys. Res., 109, C12003, doi:10.1029/2004JC002378.

Donelan, M. A., B. K. Haus, N. Reul, W. J. Plant, M. Stiassnie, H. C. Graber, O. B. Brown, and E. S. Saltzman, 2004: On the limiting aerodynamic roughness of the ocean in very strong winds. Geophys. Res. Lett., 31, L18306, doi:10.1029/2004GL019460.

Emanuel, K. A., 1999: Thermodynamic control of hurricane intensity. Nature, 401, 665-669, doi:10.1038/44326.

Fang, G., H. Chen, Z. Wei, Y. Wang, X. Wang, and C. Li, 2006: Trends and interannual variability of the South China Sea surface winds, surface height, and surface temperature in the recent decade. J. Geophys. Res., 111, C11S16, doi:10.1029/ 2005JC003276.

Furuya, K., 1990: Subsurface chlorophyll maximum in the tropical and subtropical western Pacific Ocean: Vertical profiles of phytoplankton biomass and its relationship with chlorophyll $a$ and particulate organic carbon. Mar. Biol., 107, 529-539, doi:10.1007/BF01313438.

Hanshaw, M. N., M. S. Lozier, and J. B. Palter, 2008: Integrated impact of tropical cyclones on sea surface chlorophyll in the North Atlantic. Geophys. Res. Lett., 35, L01601, doi:10.1029/ 2007GL031862.

Hart, R. E., R. N. Maue, and M. C. Watson, 2007: Estimating local memory of tropical cyclones through MPI anomaly evolution. Mon. Wea. Rev., 135, 3990-4005, doi:10.1175/ 2007MWR2038.1.

Jian, Z., B. Huang, W. Kuhnt, and H.-L. Lin, 2001: Late quaternary upwelling intensity and East Asian monsoon forcing in the South China Sea. Quat. Res., 55, 363-370, doi:10.1006/ qres.2001.2231.

Knaff, J. A., M. DeMaria, C. R. Sampson, J. E. Peak, J. Cummings, and W. H. Schubert, 2013: Upper oceanic energy response to tropical cyclone passage. J. Climate, 26, 2631-2650, doi:10.1175/JCLI-D-12-00038.1.

Ko, D. S., S.-Y. Chao, C.-C. Wu, and I.-I. Lin, 2014: Impacts of Typhoon Megi (2010) on the South China Sea. J. Geophys. Res. Oceans, 119, 4474-4489, doi:10.1002/2013JC009785.

Kuo, Y.-C., C.-S. Chern, J. Wang, and Y.-L. Tsai, 2011: Numerical study of upper ocean response to a typhoon moving zonally across the Luzon Strait. Ocean Dyn., 61, 1783-1795, doi:10.1007/s10236-011-0459-7.

Large, W. G., J. McWilliams, and S. C. Doney, 1994: Ocean vertical mixing: A review and a model with a nonlocal boundary layer parameterization. Rev. Geophys., 32, 363-403, doi:10.1029/ 94RG01872.

Lin, I.-I., 2012: Typhoon-induced phytoplankton blooms and primary productivity increase in the western North Pacific subtropical ocean. J. Geophys. Res., 117, C03039, doi:10.1029/2011JC007626. , W. T. Liu, C.-C. Wu, J. C. H. Chiang, and C.-H. Sui, 2003a: Satellite observations of modulation of surface winds by typhoon-induced upper ocean cooling. Geophys. Res. Lett., 30, 1131, doi:10.1029/2002GL015674.

_ , and Coauthors, 2003b: New evidence for enhanced ocean primary production triggered by tropical cyclone. Geophys. Res. Lett., 30, 1718, doi:10.1029/2003GL017141.
- C.-C. Wu, I.-F. Pun, and D.-S. Ko, 2008: Upper-ocean thermal structure and the western North Pacific category 5 typhoons. Part I: Ocean features and the category 5 typhoons' intensification. Mon. Wea. Rev., 136, 3288-3306, doi:10.1175/ 2008MWR2277.1.

—, C.-H. Chen, I.-F. Pun, W. T. Liu, and C.-C. Wu, 2009a: Warm ocean anomaly, air sea fluxes, and the rapid intensification of Tropical Cyclone Nargis (2008). Geophys. Res. Lett., 36, L03817, doi:10.1029/2008GL035815.

I.-F. Pun, and C.-C. Wu, 2009b: Upper-ocean thermal structure and the western North Pacific category 5 typhoons. Part II: Dependence on translation speed. Mon. Wea. Rev., 137, 3744-3757, doi:10.1175/2009MWR2713.1.

Liu, K.-K., S.-Y. Chao, P.-T. Shaw, G.-C. Gong, C.-C. Chen, and T. Y. Tang, 2002: Monsoon-forced chlorophyll distribution and primary production in the South China Sea: Observations and a numerical study. Deep-Sea Res. I, 49, 1387-1412, doi:10.1016/S0967-0637(02)00035-3.

— , and Coauthors, 2013: Inter-annual variation of chlorophyll in the northern South China Sea observed at the SEATS station and its asymmetric responses to climate oscillation. Biogeosciences, 10, 7449-7462, doi:10.5194/bg-10-7449-2013.

Long, S.-M., S.-P. Xie, X.-T. Zheng, and Q. Liu, 2014: Fast and slow responses to global warming: Sea surface temperature and precipitation patterns. J. Climate, 27, 285-299, doi:10.1175/ JCLI-D-13-00297.1.

Mei, W., and C. Pasquero, 2012: Restratification of the upper ocean after the passage of a tropical cyclone: A numerical study. J. Phys. Oceanogr., 42, 1377-1401, doi:10.1175/JPO-D-11-0209.1.

$\longrightarrow$, and - 2013: Spatial and temporal characterization of sea surface temperature response to tropical cyclones. J. Climate, 26, 3745-3765, doi:10.1175/JCLI-D-12-00125.1.

- -1, and F. Primeau, 2012: The effect of translation speed upon the intensity of tropical cyclones over the tropical ocean. Geophys. Res. Lett., 39, L07801, doi:10.1029/2011GL050765.

_ S.-P. Xie, M. Zhao, and Y. Wang, 2015a: Forced and internal variability of tropical cyclone track density in the western North Pacific. J. Climate, 28, 143-167, doi:10.1175/ JCLI-D-14-00164.1.

,,-- F. Primeau, J. C. McWilliams, and C. Pasquero, 2015b: Northwestern Pacific typhoon intensity controlled by changes in ocean temperatures. Sci. Adv., 1, e1500014, doi:10.1126/ sciadv.1500014.

Morey, S. L., M. A. Bourassa, D. S. Dukhovskoy, and J. J. O'Brien, 2006: Modeling studies of the upper ocean response to a tropical cyclone. Ocean Dyn., 56, 594-606, doi:10.1007/ s10236-006-0085-y.

Powell, M. D., P. J. Vickery, and T. A. Reinhold, 2003: Reduced drag coefficient for high wind speeds in tropical cyclones. Nature, 422, 279-283, doi:10.1038/nature01481.

Price, J. F., 1981: Upper ocean response to a hurricane. J. Phys. Oceanogr., 11, 153-175, doi:10.1175/1520-0485(1981)011<0153: UORTAH $>2.0 . \mathrm{CO} ; 2$.

_, R. A. Weller, and R. Pinkel, 1986: Diurnal cycling: Observations and models of the upper ocean response to diurnal heating, cooling, and wind mixing. J. Geophys. Res., 91, 84118427, doi:10.1029/JC091iC07p08411.

— T. B. Sanford, and G. Z. Forristall, 1994: Forced stage response to a moving hurricane. J. Phys. Oceanogr., 24, 233-260, doi:10.1175/1520-0485(1994)024<0233:FSRTAM >2.0.CO;2.

, J. Morzel, and P. P. Niiler, 2008: Warming of SST in the cool wake of a moving hurricane. J. Geophys. Res., 113, C07010, doi:10.1029/2007JC004393. 
Savtchenko, A., D. Ouzounov, S. Ahmad, J. Acker, G. Leptoukh, J. Koziana, and D. Nickless, 2004: Terra and Aqua MODIS products available from NASA GES DAAC. Adv. Space Res., 34, 710-714, doi:10.1016/j.asr.2004.03.012.

Schade, L. R., and K. A. Emanuel, 1999: The ocean's effect on the intensity of tropical cyclones: Results from a simple coupled atmosphere-ocean model. J. Atmos. Sci., 56, 642-651, doi:10.1175/1520-0469(1999)056<0642:TOSEOT>2.0.CO;2.

Shang, S., and Coauthors, 2008: Changes of temperature and biooptical properties in the South China Sea in response to Typhoon Lingling, 2001. Geophys. Res. Lett., 35, L10602, doi:10.1029/2008GL033502.

Shay, L. K., G. J. Goni, and P. G. Black, 2000: Effects of a warm oceanic feature on Hurricane Opal. Mon. Wea. Rev., 128, 1366-1383, doi:10.1175/1520-0493(2000)128<1366: EOAWOF $>2.0 . \mathrm{CO} ; 2$.

Shchepetkin, A. F., and J. McWilliams, 2005: The Regional Oceanic Modeling System (ROMS): A split-explicit, free-surface, topography-following coordinate oceanic model. Ocean Modell., 9, 347-404, doi:10.1016/j.ocemod.2004.08.002.

Sun, L., Y.-J. Yang, T. Xian, Z.-M. Lu, and Y.-F. Fu, 2010: Strong enhancement of chlorophyll $a$ concentration by a weak typhoon. Mar. Ecol. Prog. Ser., 404, 39-50, doi:10.3354/ meps08477.

Tsai, Y., C.-S. Chern, and J. Wang, 2012: Numerical study of typhoon-induced ocean thermal content variations on the northern shelf of the South China Sea. Cont. Shelf Res., 42, 64 77, doi:10.1016/j.csr.2012.05.004.

Tseng, C.-M., K.-K. Liu, L.-W. Wang, and G.-C. Gong, 2009: Anomalous hydrographic and biological conditions in the northern South China Sea during the 1997-1998 El Niño and comparisons with the equatorial Pacific. Deep-Sea Res. I, 56, 2129-2143, doi:10.1016/j.dsr.2009.09.004.

Tseng, Y.-H., S. Jan, D. E. Dietrich, I.-I. Lin, Y.-T. Chang, and T.-Y. Tang, 2010: Modeled oceanic response and sea surface cooling to Typhoon Kai-Tak. Terr. Atmos. Oceanic Sci., 21, 85-98, doi:10.3319/TAO.2009.06.08.02(IWNOP).

Vincent, E. M., K. A. Emanuel, M. Lengaigne, J. Vialard, and G. Madec, 2014: Influence of upper ocean stratification interannual variability on tropical cyclones. J. Adv. Model. Earth Syst., 6, 680-699, doi:10.1002/2014MS000327.

Walsh, K. J. E., P. Sandery, G. B. Brassington, M. Entel, C. Siegenthaler-LeDrian, J. D. Kepert, and R. Darbyshire, 2010: Constraints on drag and exchange coefficients at extreme wind speeds. J. Geophys. Res., 115, C09007, doi:10.1029/ 2009JC005876.

Wentz, F. J., C. Gentemann, D. Smith, and D. Chelton, 2000: Satellite measurements of sea surface temperature through clouds. Science, 288, 847-850, doi:10.1126/science.288.5467.847.

Wu, C.-C., C.-Y. Lee, and I.-I. Lin, 2007: The effect of the ocean eddy on tropical cyclone intensity. J. Atmos. Sci., 64, 35623578, doi:10.1175/JAS4051.1.

Xie, S.-P., Q. Xie, D. Wang, and W. T. Liu, 2003: Summer upwelling in the South China Sea and its role in regional climate variations. J. Geophys. Res., 108, 3261, doi:10.1029/2003JC001867.

Yang, Y.-J., L. Sun, A.-M. Duan, Y.-B. Li, Y.-F. Fu, Y.-F. Yan, Z.-Q. Wang, and T. Xian, 2012: Impacts of the binary typhoons on upper ocean environments in November 2007. J. Appl. Remote Sens., 6, 063583, doi:10.1117/1.JRS.6.063583.

Ye, H. J., Y. Sui, D. L. Tang, and Y. D. Afanasyev, 2013: A subsurface chlorophyll a bloom induced by typhoon in the South China Sea. J. Mar. Syst., 128, 138-145, doi:10.1016/j.jmarsys.2013.04.010.

Zhao, H., D. Tang, and Y. Wang, 2008: Comparison of phytoplankton blooms triggered by two typhoons with different intensities and translation speeds in the South China Sea. Mar. Ecol. Prog. Ser., 365, 57-65, doi:10.3354/meps07488.

Zheng, G. M., and D. Tang, 2007: Offshore and nearshore chlorophyll increases induced by typhoon winds and subsequent terrestrial rainwater runoff. Mar. Ecol. Prog. Ser., 333, 61-74, doi:10.3354/meps333061. 